\title{
O cooperativismo e o desenvolvimento local: um estudo da Cooperativa de Crédito Sicredi Serrana RS - unidade de atendimento de Boa Vista do Sul (RS) no período de 1997-2010
}

\author{
Márcia Scudella* \\ Angélica Massuquetti** \\ Mosar Leandro Ness ${ }^{* * *}$
}

Resumo: Este estudo analisa a contribuição socioeconômica da cooperativa de crédito Sicredi Serrana RS, unidade de atendimento de Boa Vista do Sul (RS), no desenvolvimento local do município (1997-2010). A metodologia compôs-se na pesquisa bibliográfica, na coleta de informações nas bases de dados FEE e IPEADATA e na utilização do software Gretl 1.9.12. para a estimação do modelo econométrico. Os resultados revelaram que a cooperativa contribuiu para o desenvolvimento socioeconômico do município em 14,91\%, após sua implantação, em 2003. O setor Agricultura e de Serviçostambém contribuíramneste processo de crescimento, respectivamente, em $0,53 \%$ e $0,38 \%$.

Palavras-Chave: Cooperativa de Crédito. Desenvolvimento Local. Sicredi Serrana RS.

\section{Cooperativism and local development: a study of the Credit Cooperative Sicredi Serrana RS - assisting unit of Boa Vista do Sul (RS) in the period 1997-2010}

Abstract: The paper analyzes the socio-economic contribution of the credit cooperative SicrediSerrana RS, assisting unit of Boa Vista do Sul (RS), in the local development of the city (1997-2010). The methodology comprehended the literature research, the gathering of information in databases and FEE and IPEADATA and the use of Gretl 1.9.12. Software for the econometric model estimation. The results revealed that the cooperative contributed to the socioeconomic development of the city in $14.91 \%$, after its inception in 2003 . The Agriculture and Service sectors also assisted in the process, contributing to growth, respectively, in $0.53 \%$ and $038 \%$.

Keywords: Credit Cooperative. Local Development. Sicredi Serrana RS.

Classificação JEL: P13, R11.

\section{Introdução}

O cooperativismo é um modelo de organização econômica e social que existe desde a antiguidade. A divisão das tarefas e a cooperação tornam os homens mais eficientes na produção de determinado bem, como afirmado por Adam Smith no estudo da divisão do trabalho (SMITH, 1985). Este movimento originou-se na Inglaterra, em meio à Revolução Industrial do século XIX,

\footnotetext{
* Economista pela Universidade do Vale do Rio dos Sinos (UNISINOS) e Secretária de Administração e Fazenda da Prefeitura Municipal de Coronel Pilar (Rio Grande do Sul). E-mail: marcia.scudella@ hotmail.

** Professora no Programa de Pós-Graduação em Economia (PPGE) da Universidade do Vale do Rio dos Sinos (UNISINOS). E-mail: angelicam@unisinos.br.

*** Professor no Curso de Ciências Econômicas da Universidade de Caxias do Sul (UCS) e Doutorando em Economia do Desenvolvimento (PUCRS). E-mail: mlness@ucs.br.
} 
através da ação popular de tecelões que buscavam uma maior autonomia econômica (OLIVEIRA, 1984). Presente, há mais de dois séculos em economias desenvolvidas, o mesmo pode ser deparado com maior expressividade na Europa e na América do Norte, destacando-seno ramo do crédito (SCHARDONG, 2002).

Com um século a menos de experiência, o Brasil apresenta-se de forma modesta no segmento se comparado a outros países do mundo, especialmente países europeus, como França, Alemanha e Holanda. Na década de 1980, a trajetória promissora do cooperativismo foi interrompida devido algumas restrições impostas ao seu funcionamento, privilegiando os bancos oficiais, como instrumentos canalizadores de recursos em detrimento das cooperativas (MEINEN; PORT, 2012). Contudo, a década de 1990 foi marcada pelo início da recuperação das cooperativas de crédito (PINHEIRO, 2008). Atualmente, as cooperativas de crédito estão entre as dez maiores instituições financeiras do país em termos de ativos financeiros (BANCO CENTRAL DO BRASIL - BACEN, 2011 apud PORTAL DO COOPERATIVISMO DE CRÉDITO, 2012).

Além de ser um instrumento que oferece recursos financeiros, as cooperativas de crédito são vistas como um importante difusor do desenvolvimento regional. Frantz (2003) destaca que as cooperativas são fenômenos que brotam da articulação e da associação de indivíduos que identificam-se por interesses ou necessidades, com vista a objetivos e resultados, normalmente, de ordem econômica. Neste aspecto, ressalta-se que o desenvolvimento regional é compreendido a partir de uma perspectiva endógena, ou seja, os fatores internos à região são capazes de transformar-se em impulso de crescimento econômico.

O Conselho Regional de Desenvolvimento (COREDE) Serra, localizado na região nordeste do Estado do Rio Grande do Sul, caracteriza-se por elevadas taxas de crescimento e de desenvolvimento socioeconômico e pela presença de inúmeras experiências cooperativas, suscitando o estudo das mesmas e sua influência sobre o desenvolvimento regional. Boa Vista do Sul é um dos 32municípios integrantes desse COREDE, que tem na produção de frango de corte sua principal fonte de economia. Diante disso, a presença de uma cooperativa de crédito incitaem alguns questionamentos: A cooperativa de crédito está cumprindo seu papel de difusora econômica e social no município? Qual a influência que a cooperativa exerce sobre esta comunidade, desde sua implantação?

O elemento desta pesquisa fora a cooperativa de crédito Sicredi Serrana RS, unidade de atendimento - Boa Vista do Sul, tendo como objetivo geral a análise da contribuição 
socioeconômica da cooperativa no desenvolvimento local do município, supra citado, no período 1997-2010. Os objetivos específicos denotam na identificação da influência do cooperativismo de crédito no desenvolvimento socioeconômico e as principais referências teóricas do desenvolvimento regional e local, analisando a influência socioeconômica da cooperativa de crédito Sicredi Serrana RS, unidade - Boa Vista do Sul, no desenvolvimento local do município de Boa Vista do Sul.

A metodologia empregada funde-se na pesquisa bibliográfica, que subsidioua efetivação do primeiro objetivo específico. No entanto, a coleta de dados acerca da influência da cooperativa de crédito fundamentou-se em bases como a Fundação de Economia e Estatística (FEE) e IPEADATA, base de dados do Instituto de Pesquisa Econômica Aplicada (IPEA), no período de 1997 a 2010. Além disso, utilizou-se o software Gretl 1.9.12 para desenvolver o modelo econométrico explicativo.

$\mathrm{O}$ artigo está estruturado em mais quatro seções, além desta Introdução. Na segunda seção foi analisado o cooperativismo de crédito e o desenvolvimento. Na terceira seção foram apresentadas algumas características socioeconômicas e históricas do município de Boa Vista do Sul e da cooperativa de crédito Sicredi Serrana RS, unidade de atendimento de Boa Vista do Sul. Na quarta seção demonstraram-se os procedimentos metodológicos utilizados, bem como os resultados encontrados. E, por fim, na quinta seção, foram apresentadas as principais conclusões do estudo.

\section{O cooperativismo de crédito e o desenvolvimento}

Nesta seção são apresentados aspectos teóricos do desenvolvimento regional e local com o intuito de explanar como o cooperativismo de crédito pode e tem contribuído para o desenvolvimento regional. Além disso, são ressaltados alguns estudos empíricos acerca do cooperativismo de crédito.

\subsection{O desenvolvimento a partir do cooperativismo de crédito}

A definição de desenvolvimento regional é complexa, pois o processo de desenvolvimento econômico não ocorre da mesma forma em todas as regiões, ele é descontínuo. A concentração econômica, as descontinuidades e as desigualdades regionais, ao menos nas fases iniciais, são inevitáveis e uma região, devido suas particularidades, terá um destaque diferenciado em detrimento a outras, devido a apresentação de maior potencial de crescimento e dinamismo. No contexto em que essa pesquisa foi desenvolvida, o 
desenvolvimento local pode ser entendido como um processo que mobiliza pessoas e instituições, buscando a transformação da economia e da sociedade existente, criando oportunidades de trabalho e de renda superando dificuldades para favorecer a melhoria das condições de vida da população vigente (JESUS, 2003).

O processo de desenvolvimento pode resultar de iniciativas endógenas ou exógenas. As teorias clássicas ou tradicionais destacam a presença de uma força motriz de caráter exógeno, que influenciam as demais atividades econômicas por meio de encadeamentos, mais conhecido como paradigma "centro-abaixo", pois essas forças impulsoras advêm das regiões centrais (LIMA; OLIVEIRA, 2003). Há três teorias que podem ser enquadradas nesta definição: a Teoria da Base de Exportação, a Teoria da Difusão e a Teoria do Pólo de Crescimento.

A proposição central da Teoria da Base de Exportação é de que as exportações são a principal força desencadeadora do processo de desenvolvimento local ou regional, sendo que o crescimento depende da dinamicidade das atividades econômicas básicas que incentivam o desenvolvimento de atividades complementares. Assim, ocorre uma troca, onde as atividades básicas vendem seus produtos em outras regiões, sendo, portanto, a força motriz da economia, enquanto as atividades complementares dão suporte às atividades básicas (LIMA; OLIVEIRA, 2003). Um aumento na base de exportação estabelece um efeito multiplicador e todas as demais atividades econômicas não voltadas à exportação, especialmente as de comércio e serviços, são induzidas pela expansão ou declínio das indústrias de exportação (NORTH, 1977).

Segundo a Teoria da Difusão, o desenvolvimento dar-se-á com a industrialização e com a concentração das atividades em reduzido número de grandes centros urbanos, que irradiam efeitos capazes de dinamizar a economia das demais regiões. Por fim, a Teoria do Pólo de Crescimento, desenvolvida por François Perroux, também está fundamentada na ideia de força motriz. A inserção de uma atividade motriz, normalmente uma indústria, em uma região, resultará em efeitos positivos e negativos ao local. À medida que tais efeitos vão se concentrando, a atividade motriz se tornará um pólo propulsor da economia da região, sendo que este desenvolvimento dependerá do nível e da qualidade dos efeitos positivos e negativos (LIMA; OLIVEIRA, 2003).

Por outro lado, há iniciativas endógenas, conhecidas como "desde baixo", que procuram analisar o desenvolvimento regional, dando destaque aos fatores internos à região, capazes de transformar um impulso externo de crescimento econômico em desenvolvimento 
para toda a sociedade. Este paradigma ressalta que a população local precisa ser ouvida: "Pensar em desenvolvimento regional é, antes de qualquer coisa, pensar na participação da sociedade local no planejamento contínuo da ocupação do espaço e na distribuição dos frutos do processo de crescimento" (LIMA; OLIVEIRA, 2003, p. 3).

Para Buarque (2002), o processo endógeno no desenvolvimento local leva ao dinamismo econômico e à melhoria da qualidade de vida da população em pequenas unidades territoriais e agrupamentos humanos. Assim, haverá uma participação efetiva da população na definição de seu rumo e sua forma de desenvolvimento, sendo que a forma de organização que facilita esta dinâmica social é a cooperativa. Para a construção do desenvolvimento local a participação da comunidade é fundamental, o ser humano constitui o papel de sujeito nesse processo nas mais diversas formas de realização e organização, tendo a cooperação como primordial.

Ao relacionar cooperação e desenvolvimento local, Frantz (2003) argumenta que organizações cooperativas são fenômenos que nascem da articulação e da associação de indivíduos que se identificam por interesses ou necessidades, buscando seu fortalecimento pela instrumentalização, com vista em objetivos e resultados, normalmente, de ordem econômica. A cooperação, além de, compreender os interesses e necessidades frente à produção e distribuição de bens e riquezas, engloba elementos sociais, culturais e políticos. Elementos estes que fazem parte da economia como um todo e que a partir da cooperativa renasce o local como base do processo de desenvolvimento. Porém, mais que o local, a organização cooperativa carrega dentro dela a força política que permite recolocar o homem e não o capital, no centro da dinâmica da economia (FRANTZ, 2003).

Nas cooperativas, o capital tem um papel de respaldo, a individualidade cede espaço para a construção conjunta dos objetivos (MEINEN; PORT, 2012). Os resultados econômicos obtidos são proporcionais às operações entre seus cooperados, contribuindo para a efetiva distribuição e geração de renda, além da criação de empregos (BIALOSKORSKI NETO, 2002). Segundo Boesche (2005), o cooperativismo apresenta duas dimensões que são essenciais para o seu perfeito desenvolvimento: uma dimensão social, relacionada às pessoas, e uma dimensão econômica, relacionada às empresas.

Segundo Rech (2000, p. 22):

A cooperativa é uma iniciativa autônoma de pessoas, caracterizada por possuir dupla natureza, partindo de fato de a mesma ser simultaneamente uma entidade social (um grupo organizado de pessoas) e uma unidade econômica (uma empresa financiada, administrada e controlada comunitariamente), tendo como objetivo principal o de ser utilizada diretamente pelos associados como meio de prover bens e serviços que 
necessitam e que não conseguem obter individualmente em condições semelhantes.

$\mathrm{Na}$ dimensão social, a cooperativa preocupa-se com o bem-estar e com o fortalecimento do ser humano na comunidade. Enquanto a dimensão econômica está voltada a rentabilizar a atividade individual do associado. Assim, chega-se à conclusão que, segundo Silva, Lourenço e Salanek Filho (2006), o modelo cooperativista caracteriza-se por promover a aproximação e a interação dos agentes no ambiente em que estão inseridos.

No evento Rio Cooperativo 2000, em 04 de dezembro 2000, o ex-presidente Fernando Henrique Cardoso, em seu pronunciamento na cerimônia de abertura, traduziu com clareza que numa cooperativa a questão social se confunde com a econômica:

A cooperativa, como uma empresa, caracteriza-se por aliar diretamente, na mesma organização cooperativa, dois aspectos fundamentais do desenvolvimento sustentável: a racionalidade econômica e o sentido da solidariedade social. Um híbrido de empresa e organização do terceiro setor, uma empresa com o coração. (MEINEN; PORT, 2012, p. 50).

De acordo com Meinen e Port (2012), há uma preocupação em gerar progresso conforme a aptidão das populações e de acordo com o potencial econômico da região cooperativada. As cooperativas apresentam um caráter comunitário, colocam-se como uma alternativa socioeconômica, baseada em valores e princípios, que tem por objetivo a construção de uma vida melhor para seus associados de forma equilibrada, inclusa e sustentável. Essa questão é tão importante na organização cooperativista que se constitui no sétimo princípio universal: interesse pela comunidade.

Assim como os demais ramos cooperativos, as cooperativas de crédito, objeto desse estudo, têm o associado como próprio dono do empreendimento e destinatário das soluções. Enquanto na atividade bancária tradicional o usuário simboliza um terceiro, chamado de cliente, onde não há qualquer compromisso entre ele e a empresa. Esta seria então a diferença essencial (MEINEN; PORT, 2012).

As cooperativas não destinam seus recursos para fora da comunidade em que estão inseridas, pelo contrário, os recursos são reinvestidos no próprio local, como afirmam Meinen e Port (2012, p. 54):

Como instrumento de desenvolvimento local, as cooperativas de crédito asseguram a reciclagem dos recursos nas próprias comunidades. Ou seja, o resultado monetário do que se gera é reinvestido ali mesmo, produzindo novas riquezas. Além disso, as entidades têm plena autonomia para ajustar a sua política creditícia e de gestão da poupança à realidade do lugar. Essa liberdade permite acompanhar adequadamente o ciclo econômico de cada região e respeitar as suas aptidões e potencialidades socioeconômico-culturais, com geração e incremento de renda, estimulando, ainda, a fixação dos jovens nas próprias comunidades. 
De forma sintética, o ciclo virtuoso do cooperativismo de crédito pode ser apresentado da seguinte forma, segundo Meinen e Port (2012, p. 54):

\begin{abstract}
Se os recursos dos cidadãos e das empresas forem destinados às cooperativas, esta os realocam na mesma região; redistribuídos, geram renda e aumentam o poder aquisitivo da população, que passa a consumir mais; em decorrência, há incremento no faturamento das empresas; vendendo mais, as empresas abrem novas vagas de trabalho, absorvendo especialmente o público jovem; o aumento nas vendas também repercute na arrecadação de impostos; com mais recursos, o poder público investe em infraestrutura e outros projetos de desenvolvimento econômico e social, o que faz ampliar a capacidade produtiva, gerando novas riquezas. O resultado final é a melhora na qualidade de vida na área de abrangência da cooperativa.
\end{abstract}

As cooperativas de crédito, como organização local, captando e alocando poupanças, são exponenciais parceiros do desenvolvimento endógeno. Em razão de seus valores e princípios, não selecionam as melhores praças e os cidadãos mais abastados, ideologia de muitas instituições financeiras. Sendo assim, cumprem um duplo papel: promover o desenvolvimento econômico e assegurar o exercício da cidadania pela inclusão financeira (MEINEN; PORT, 2012).

\title{
2.2. Pesquisas empíricas acerca do cooperativismo de crédito
}

O cooperativismo de crédito é considerado um sistema financeiro alternativo, que possibilita o acesso das pessoas aos serviços financeiros, independentemente de sua renda, além de conceder crédito aos associados, que são ao mesmo tempo donos e usuários do negócio. O foco é proporcionar maiores benefícios aos associados por meio de produtos e serviços com menor custo que o mercado, não visando somente lucro. Devido a sua preocupação não só econômica, mas principalmente social, as cooperativas são consideradas importantes na sociedade e têm sido alvo recorrente de pesquisas. Esta subseção pretende apresentar alguns estudos que abordam o cooperativismo de crédito.

Presente há mais de 100 anos no Brasil, o cooperativismo de crédito foi introduzido pelo Padre Jesuíta Theodor Amstadt com o objetivo de fortalecer a classe trabalhadora rural. De acordo com Machado e Schmidt (2012), o Cooperativismo de Crédito vem incentivando a socialização do Sistema Financeiro Nacional, através da evolução de sua estrutura, tornandose assim uma terceira alternativa para o sistema bancário. Diante dessa realidade, os autores buscam mostrar a atuação das Cooperativas de Crédito no SFN e sua evolução desde a criação da primeira cooperativa de crédito no Brasil baseando seu estudo na pesquisa bibliográfica e documental. Para isso, apresentam três exemplos de Sistemas Cooperativos atuais. O primeiro sistema apresentado é o SICOOB, com 1,7 milhões de associados, em 2010 e fechou este ano 
com $\mathrm{R} \$$ 9,4 bilhões em operações de crédito, $\mathrm{R} \$ 7,8$ bilhões em depósitos, $\mathrm{R}$ \$ 4,6 bilhões em patrimônio de referência, $\mathrm{R} \$ 301$ milhões de resultado anual e $\mathrm{R}$ \$ 15,9 bilhões em ativos totais. O segundo é o SICREDI, com 1,5 milhões de associados, R 5 bilhões em operações de crédito, $\mathrm{R} \$ 10$ bilhões em depósitos, $\mathrm{R}$ \$ 2 bilhões em patrimônio líquido, $\mathrm{R}$ \$ 267 milhões de resultado anual e $\mathrm{R} \$ 17$ bilhões de ativos (2010). E, por fim, a UNICRED, composta, em 2008, por 206.091 associados e 2.519 funcionários, em relação aos depósitos totais possui R \$ 3,781 bilhões, um patrimônio líquido de R \$ 1,446 bilhões e sobras acumuladas de R 245 milhões, o ativo total é de $\mathrm{R} \$ 5,401$ bilhões e os empréstimos representam $\mathrm{R} \$$ 3,090 bilhões. Machado e Schmidt (2012) afirmam que, a partir dos dados e informações coletados, as cooperativas tendem a buscar um equilíbrio entre a situação econômica e social. Além disso, elas podem ser consideradas como um distribuidor de renda, o oposto dos bancos comerciais, que visam apenas no lucro.

Annibal e Koyama (2011) visaram comparar as taxas de juros praticadas por cooperativas de crédito e bancos (múltiplos e comerciais) a fim de verificar se existia ou não diferença nas taxas cobradas nas operações de crédito pessoal sem consignação. Além disso, também averiguaram os efeitos dessa diferença nos juros cobrados pelos bancos em operações similares. A partir de dados obtidos no Sistema de Informações de Crédito (SCR), o estudo comprovou que as taxas cobradas pelas cooperativas eram, em média, menores, sendo 30,3\% a.a., enquanto que nos bancos $61,0 \%$ a.a. Porém, não havia indícios de que a concorrência exercida pelas cooperativas era suficiente para reduzir as taxas cobradas pelos bancos. Outros resultados encontrados pelos autores, tendo como base o Instituto Brasileiro de Geografia e Estatística (IBGE), foram que as cooperativas de crédito tendem a se instalar em áreas com perfil mais rural, taxas de homicídios mais reduzidas, menor densidade demográfica, melhor qualidade do sistema judiciário e maior número de domicílios com renda per capita entre meio e três salários mínimos. Ou seja, regiões com incidência de alto capital social e onde as relações sociais entre os habitantes são mais próximas elevando o grau de confiança, fator primordial na implementação, e no sucesso de estabelecimentos cooperativos.

As cooperativas de crédito contribuem para o desenvolvimento regional devido ao seu papel social de mediadora financeira. Um dos recursos é a poupança, utilizada para investimentos na própria região, promove a reciclagem dos recursos locais, evitando, assim, a transferência de economia para os grandes centros. Ou seja, há o aproveitamento regional de grande parte dos recursos econômicos acumulados sob a forma de depósitos, que retornam para a sua própria origem geográfica na forma de operações de crédito. Diante disso, Fonseca 
et al. (2009) buscaram demonstrar os benefícios do cooperativismo de crédito como instrumento de desenvolvimento regional. A pesquisa baseou-se em análises quantitativas descritivas e no estudo de caso da Cooperativa de Crédito de Livre Admissão Campos da Mantiqueira Ltda. - SICOOB Credicampo -, localizada no estado de Minas Gerais, e na comparação da atuação de outras instituições financeiras atuantes no local no período de julho de 2008. Para uma melhor demonstração das movimentações financeiras de operações de crédito e depósitos, utilizou-se o software Signet. Em julho de 2008, a participação no mercado de operações de crédito dos municípios nos quais onde as cooperativas de crédito atuavam era de 12,13\%. Já nos depósitos, o índice de participação de mercado do mesmo mês era de $15,45 \%$. Os resultados obtidos destacam que a atuação das cooperativas de crédito, enquanto intermediadoras financeiras, não impactam de forma relevante na economia local. Contudo, é notória a participação da cooperativa de crédito, que ao contrário dos bancos, devolve grande parte dos recursos depositados para seus locais de origem sob a forma de operações de crédito, contribuindo para o desenvolvimento regional.

No que diz respeito à competitividade das cooperativas de crédito, Bertossoet al. (2008) destacaram que as mesmas possuem diferenciais únicos, seja pela sua natureza societária, seja pela sua atuação em Sistema. Alguns elementos, como relacionamento, instituição financeira da comunidade, modelo agregador de renda, autonomia das cooperativas, organização sistêmica, responsabilidade solidária e ato cooperativo são características próprias das cooperativas de crédito e servem como um diferencial competitivo. Por meio da análise bibliográfica e do estudo de caso, os autores buscaram identificar os diferenciais competitivos de uma cooperativa de crédito, localizada no Rio Grande do Sul, a fim de identificar os pontos chave para a busca de novos associados e a melhoria no atendimento das necessidades de seus associados. Para a pesquisa utilizou-se dois modelos de questionários, um para associados e outro para não associados, na faixa etária de 16 a 25 anos. Assim, verificaram que a unidade de atendimento não atende completamente o seu associado, pois as médias atribuídas à importância foram superiores às médias obtidas no desempenho, necessitando de melhorias em todos os diferenciais competitivos. Os diferenciais que fazem a diferença na escolha de uma instituição para gerenciar as economias, o contribuinte acaba por dar importância ao atendimento dentro da unidade, a agilidade na tomada de decisões, o fato de possuir colaboradores do próprio município e por não ser passível de falência. Por outro lado, os diferençais competitivos que necessitam maior atenção por parte da unidade analisada foram: ato cooperativo, relacionamento e organização sistêmica. 
Franz (2006) destacou que o cooperativismo de crédito tem apresentado um crescimento expressivo nos últimos anos e, por isso, vem assumindo um papel de destaque no SFN. Diante disso, buscou analisar a contribuição das cooperativas de crédito para a eficiência econômica e eficácia social. Para chegar às conclusões, o estudo foi desenvolvido por meio da técnica de pesquisa bibliográfica e documental, a partir de normativos do BACEN e do CMN. O cooperativismo foi percebido efetivamente como um instrumento de organização e desenvolvimento da sociedade, sendo a educação cooperativista fundamental para este processo. A partir do momento em que o indivíduo compreende seu papel nesse contexto, a inclusão econômica e social se perpetua. Contudo, primeiramente, é necessário alcançar a viabilidade econômico-financeira do empreendimento cooperativo, destacando a estruturação das cooperativas em Sistemas Cooperativos, a profissionalização dos dirigentes e do quadro funcional e o constante investimento em tecnologia da informação. Além disso, o Estado deve participar como promotor de incentivo através de leis que não registram a capacidade das cooperativas. De acordo com Franz (2006), a eficiência econômica e a eficácia social das cooperativas de crédito são observadas a partir da informação do BACEN, onde a carteira de crédito das cooperativas passou de $\mathrm{R} \$ 5,524$ bilhões para $\mathrm{R} \$$ 8,285 bilhões, entre junho de 2003 e dezembro de 2004, um crescimento de $50 \%$.

O Quadro 1 apresenta um resumo dos estudos empíricos analisados, onde são expostos os autores, os objetivos, os períodos de análise, a região, a metodologia utilizada e os principais resultados de cada pesquisa. 
Quadro 1: Revisão bibliográfica

\begin{tabular}{|c|c|c|c|c|c|}
\hline Autor(es) & Objetivo & Período & Região & Metodologia & Resultados \\
\hline $\begin{array}{c}\text { Machado } \\
\text { e Schmidt } \\
\text { (2012) }\end{array}$ & $\begin{array}{l}\text { Mostrar a atuação das } \\
\text { Cooperativas de } \\
\text { Crédito no SFN e sua } \\
\text { evolução desde a } \\
\text { criação da primeira } \\
\text { cooperativa de crédito } \\
\text { no Brasil. } \\
\end{array}$ & $\begin{array}{l}2008- \\
2010\end{array}$ & Brasil & $\begin{array}{c}\text { Pesquisa } \\
\text { bibliográfica } \\
\text { e } \\
\text { documental. }\end{array}$ & $\begin{array}{l}\text { As cooperativas tendem a buscar um } \\
\text { equilíbrio entre a situação econômica } \\
\text { e social. Além disso, elas podem ser } \\
\text { consideradas como um distribuidor de } \\
\text { renda, o oposto dos bancos } \\
\text { comerciais, que visam apenas no } \\
\text { lucro. }\end{array}$ \\
\hline $\begin{array}{c}\text { Annibal e } \\
\text { Koyama } \\
(2011)\end{array}$ & \begin{tabular}{|} 
Comparar as taxas de \\
juros praticadas por \\
cooperativas de crédito \\
e bancos a fim de \\
verificar a existência ou \\
não de diferença nas \\
operações de crédito \\
pessoal sem \\
consignação. \\
\end{tabular} & Dez./2010 & Brasil & $\begin{array}{l}\text { Teste de } \\
\text { comparação } \\
\text { de médias, } \\
\text { estatístico. }\end{array}$ & $\begin{array}{l}\text { As taxas cobradas pelas cooperativas } \\
\text { eram, em média, menores, sendo } \\
30,3 \% \text { a.a., enquanto que nos bancos } \\
61,0 \% \text { a.a.. Porém, não há indícios de } \\
\text { que a concorrência exercida pelas } \\
\text { cooperativas seja suficiente para } \\
\text { reduzir as taxas cobradas pelos } \\
\text { bancos. }\end{array}$ \\
\hline $\begin{array}{c}\text { Fonseca } \\
\text { et al. } \\
(2009)\end{array}$ & $\begin{array}{l}\text { Demonstrar os } \\
\text { benefícios do } \\
\text { cooperativismo de } \\
\text { crédito como } \\
\text { instrumento de } \\
\text { desenvolvimento } \\
\text { regional. }\end{array}$ & Jul./2008 & $\begin{array}{l}\text { Minas } \\
\text { Gerais }\end{array}$ & $\begin{array}{l}\text { Análise } \\
\text { quantitativa } \\
\text { descritiva, } \\
\text { estudo de } \\
\text { caso e } \\
\text { utilização do } \\
\text { software } \\
\text { Signet. }\end{array}$ & $\begin{array}{l}\text { É notória a participação da } \\
\text { cooperativa de crédito, que ao } \\
\text { contrário dos bancos, devolve grande } \\
\text { parte dos recursos depositados para } \\
\text { seus locais de origem sob a forma de } \\
\text { operações de crédito, contribuindo } \\
\text { para o desenvolvimento regional. }\end{array}$ \\
\hline $\begin{array}{c}\text { Bertossoet } \\
\text { al. }(2008)\end{array}$ & $\begin{array}{l}\text { Identificar os } \\
\text { diferenciais } \\
\text { competitivos de uma } \\
\text { cooperativa de crédito } \\
\text { para a busca de novos } \\
\text { associados e melhorar o } \\
\text { atendimento de seus } \\
\text { associados. }\end{array}$ & Abr./2007 & $\begin{array}{c}\text { Rio } \\
\text { Grande } \\
\text { do Sul }\end{array}$ & $\begin{array}{c}\text { Análise } \\
\text { bibliográfica } \\
\text { e estudo de } \\
\text { caso. }\end{array}$ & $\begin{array}{l}\text { Os diferencias que apresentam um } \\
\text { maior índice de importância foram o } \\
\text { atendimento dentro da unidade, a } \\
\text { agilidade na tomada de decisões, o } \\
\text { fato de possuir colaboradores do } \\
\text { próprio município e por não ser } \\
\text { passível de falência. Por outro lado, } \\
\text { os diferenciais que necessitam de } \\
\text { maior atenção foram ato cooperativo, } \\
\text { relacionamento e organização } \\
\text { sistêmica. }\end{array}$ \\
\hline $\begin{array}{l}\text { Franz } \\
(2006)\end{array}$ & $\begin{array}{c}\text { Analisar a contribuição } \\
\text { das cooperativas de } \\
\text { crédito para a eficiência } \\
\text { econômica e eficácia } \\
\text { social. }\end{array}$ & $\begin{array}{l}1996- \\
2004\end{array}$ & Brasil & $\begin{array}{c}\text { Pesquisa } \\
\text { bibliográfica } \\
\text { e documental } \\
\text { a partir de } \\
\text { normativos } \\
\text { do BACEN e } \\
\text { do CMN. }\end{array}$ & $\begin{array}{l}\text { O cooperativismo foi percebido } \\
\text { efetivamente como um instrumento de } \\
\text { organização e desenvolvimento da } \\
\text { sociedade, sendo a educação } \\
\text { cooperativista fundamental para este } \\
\text { processo. A eficiência econômica e a } \\
\text { eficácia social são observadas a partir } \\
\text { da carteira de crédito que passou de } \mathrm{R} \$ \\
5,524 \text { bilhões para R } \$ 8,285 \text { bilhões, } \\
\text { entre junho de } 2003 \text { e dezembro de } \\
2004 \text {, um crescimento de } 50 \% \text {. }\end{array}$ \\
\hline
\end{tabular}

Fonte: Elaborado pelos autores.

Conforme exposto nessa seção, o cooperativismo de crédito é visto como umimportante promotor do desenvolvimento regional seja no âmbito econômico ou no âmbito social. A participação direta e indireta das pessoas por serem ao mesmo tempo donos e usuários da cooperativa é um diferencial que contribui para que isso ocorra. Os estudos 
apresentados na última subseção comprovam o que foi discutido inicialmente, além de mostrar diferentes visões sobre o cooperativismo de crédito. Após a exposição teórica, a próxima seção apresenta o modelo econométrico desenvolvido para explicar o desenvolvimento socioeconômico de Boa Vista do Sul a partir da cooperativa de crédito Sicredi Serrana RS, unidade de atendimento do mesmo município.

\section{Boa Vista do Sul e a Cooperativa de Crédito Sicredi Serrana RS: aspectos socioeconômicos e históricos}

Nesta seção são apresentadas algumas características socioeconômicas e históricas do município de Boa Vista do Sul e da cooperativa de crédito Sicredi Serrana RS, unidade de atendimento de Boa Vista do Sul.

\subsection{Caracterização de Boa Vista do Sul}

O município de Boa Vista do Sul situa-se na região da Serra Gaúcha e pertence à Encosta Superior do Nordeste, na Microrregião de Caxias do Sul, e ao Conselho Regional de Desenvolvimento Econômico Serra (COREDE Serra). O COREDE Serra apresenta uma área de $6.947,5 \mathrm{~km}^{2}$ (2013), englobando 32 municípios e uma população total de 890.903 habitantes, tendo como densidade demográfica 128,1 hab./km² (2013). Este Conselho apresenta uma das melhores condições socioeconômicas do estado, tendo uma taxa de analfabetismo de 2,66\% (2010), uma expectativa de vida ao nascer de 74,59 anos (2000) e um coeficiente de mortalidade infantil de 10,88 por mil nascidos vivos (2012). O PIBpm do COREDE Serra foi de R \$ mil 30.543.244,00, enquanto o seu PIB per capita foi de $\mathrm{R} \$$ 34.642,00 (2012) e as exportações totais foram de US\$ FOB 1.543.605.180,00 (2014). (FEE, 2015a). Quanto aos indicadores do COREDE Serra destaca-se o Índice de Desenvolvimento Socioeconômico (IDESE), atingindo um índice de 0,815, em 2013, mantendo-se na liderança do ranking dos COREDES gaúchos. Isso demonstra que as condições socioeconômicas dos municípios que pertencem ao COREDE são superiores àquelas encontradas em outros municípios do Estado. Nos demais blocos, como educação, renda e saúde, os índices apresentados são, respectivamente: 0,728 ( $5^{\circ}$ lugar), 0,844 ( $1^{\circ}$ lugar) e 0,874 ( $1^{\circ}$ lugar). (FEE, 2015b).

Boa Vista do Sul foi colonizada por imigrantes italianos que se dedicaram à atividade agrícola. Sua emancipação ocorreu em 22 de outubro de 1995, por meio de um plebiscito, sendo resultado da união de dois distritos pertencentes ao município de Garibaldi, 27 da Boa 
Vista e São José de Azevedo Castro, e por distrito pertencente ao município de Barão, Carolina. (LUCIAN, 2003). O município se localiza entre a Serra Gaúcha e o Vale do Taquari (135 km de Porto Alegre, $69 \mathrm{~km}$ de Caxias do Sul e $40 \mathrm{~km}$ de Lajeado, municípios polos microrregionais). Sua área é de 93,2 km² e compreende 20 localidades, com uma população de 2.809 habitantes e uma densidade demográfica de 30,1 hab./ $\mathrm{km}^{2}$ (2013). Destacam-se os seguintes indicadores socioeconômicos: taxa de analfabetismo de 7,36\% (2010); expectativa de vida ao nascer de 73,11 anos (2010); coeficiente de mortalidade infantil de 0,00 por mil nascidos vivos, em 2012; PIBpm, em 2012, de R\$ mil 118.819,00; PIB per capita de 42.941,00 no mesmo ano; e exportações totais de US\$ FOB 8.956.069,00, em 2014. (FEE, 2015c). Quanto ao IDESE, o município apresenta um índice de 0,812 (2012), ocupando a $27^{\circ}$ posição no ranking dos municípios gaúchos. Os valores apresentados pelos blocos educação,

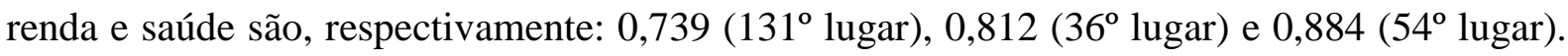
(FEE, 2015d).

É importante destacar que as propriedades do município são compostas de pequenas áreas, que variam de dois a 30 hectares, onde predomina a agricultura familiar. Sua economia está baseada no setor agropecuário, principalmente, na avicultura, com a criação de frango de corte, e na agricultura, com a produção de batata inglesa, uva, laranja, tomate, cebola, feijão, milho etc. Estas culturas agrícolas são produzidas pelos produtores familiares para atender ao seu consumo e comercializar o seu excedente nos municípios vizinhos, como Vale do Taquari, Serra Gaúcha e a capital, Porto Alegre. Outras atividades realizadas são a produção de leite, a fabricação de queijo, a criação de suínos, a produção de ovos e a criação de gado leiteiro (PEREIRA; MASSUQUETTI; KRÜTZMANN, 2012).

\subsection{Evolução histórica da Cooperativa de Crédito Sicredi Serrana RS, unidade de atendimento de Boa Vista Do Sul}

No início da década de 1980, dirigentes, diretores e associados da Cooperativa Santa Clara, diante da necessidade de financiamento dos investimentos do ramo leiteiro, viram no modelo cooperativista uma alternativa para suprir esse auxílio e buscaram a constituição de uma cooperativa de crédito, como instrumento de organização econômica da sociedade. Após, aproximadamente, cinco anos de elaboração e trabalho, em 30 de outubro de 1985 nasceu a Cooperativa de Crédito Rural de Carlos Barbosa (CREDICLARA), sendo o nome composto pela expressão CREDI acrescido do nome da cooperativa de produção que a originou, a Cooperativa Santa Clara. A primeira unidade de atendimento (UA) foi fundada em 30 de 
outubro de 1987, no município de Carlos Barbosa, conhecida, atualmente, como unidade de atendimento Júlio, por se localizar na Rua Júlio de Castilhos. Em 1993, a segunda UA instalou-se no município de Veranópolis. (SICREDI SERRANA RS, 2012).

No início, a cooperativa teve pouca expressão, sendo que sua expansão regional alavancou em 1995, com três unidades de atendimento, data também marcada pela alteração do nome fantasia para Sicredi Carlos Barbosa. Cinco anos depois, a cooperativa sofreu mais uma alteração e passou a ser conhecida, como é atualmente, por Sicredi Serrana RS. Em 2006, mais uma mudança, a Sicredi Serrana RS passou a denominar-se Cooperativa de Crédito de Livre Admissão de Associados de Carlos Barbosa, contando com 18 unidades de atendimento. E, apenas em 2012, foi realizada a primeira assembleia geral por voto delegado (SICREDI SERRANA RS, 2012).

Em 2015, a cooperativa de crédito Sicredi Serrana RS completa 30 anos de trajetória. Sua área de atuação compreende 23 municípios da Serra Gaúcha e Vale do Caí através de 28 pontos de atendimento: Barão, Bento Gonçalves (UA Centro, UA São Roque e UA Cidade Alta), Boa Vista do Sul, Bom Princípio, Carlos Barbosa (UA Júlio, UA Maurício e SUREG Sicredi Empresas), Coronel Pilar, Cotiporã, Fagundes Varela, Farroupilha, Flores da Cunha (UA Centro e UA São Gotardo), Garibaldi, Monte Belo do Sul, Nova Pádua, Nova Roma do Sul, Pinto Bandeira, Santa Tereza, São Marcos, São Pedro da Serra, São Sebastião do Caí, São Vendelino, Veranópolis, Vila Flores e Tupandi. A sede da Superintendência Regional (SUREG) é o município de Carlos Barbosa, localizado a $23 \mathrm{~km}$ de Boa Vista do Sul (SICREDI SERRANA RS, 2015).

Atualmente, dentre as 98 cooperativas de crédito que formam o Sicredi, a cooperativa é a $8^{\mathrm{a}}$ maior em recursos administrativos. Coloca à disposição dos associados e comunidade oportunidades de aplicação e poupança, com linhas de crédito e investimentos variados. Dos produtos e serviços, dispõe de: seguro, consórcio, cobrança, cartões de débito e crédito, previdência, etc. Seu maior diferencial está em ser uma instituição financeira da comunidade, onde os recursos captados de associados poupadores são reinvestidos através de linhas de crédito demandadas por associados para seus investimentos. A soma desses recursos captados e emprestados resulta em $\mathrm{R} \$ 1,55$ bilhão de ativos e contribui para fortalecer a economia da nossa região. A cooperativa conta com 81.728 associados, destes 75.267 são pessoas físicas e 6.461 são pessoas jurídicas. Seu quadro é de 339 colaboradores, considerando o presidente e o vice-presidente e desconsiderando os estagiários (SICREDI SERRANA RS, 2015). 
A unidade de atendimento de Boa Vista do Sul foi instalada pela cooperativa de crédito Sicredi Serrana RS no ano de 2003. Atualmente, a unidade de atendimento conta com seis colaboradores para atender os mais de 1.538 associados, dentre pessoa física e pessoa jurídica (SICREDI SERRANA RS, 2015).

\section{Contribuição socioeconômica da Cooperativa de Crédito Sicredi Serrana RS}

Nesta seção são apresentados os procedimentos metodológicos, como a fonte e o tratamento dos dados, a mensuração do modelo, os testes estatísticos, bem como a estimação das elasticidades com base no modelo adotado. Por fim, são analisados os resultados obtidos no estudo.

É importante destacar que a análise da cooperativa em questão baseou-se em algumas metodologias utilizadas por estudos empíricos analisados neste artigo. Assim, a partir pesquisa bibliográfica, metodologia utilizada pelos autores Bertossoet al. (2008), Franz (2006) e Machado e Schmidt (2012), buscou-se obter informações da cooperativa de crédito em análise. O estudo de Fonseca et al. (2009) auxiliou para que fosse desenvolvida a análise quantitativa descritiva das variáveis que seriam inseridas no modelo. E quanto à pesquisa desenvolvida por Annibal e Koyama (2011), esta apresentou um estudo que utiliza a econometria para análise de dados, sendo que neste artigo utilizou-se o software Gretl 1.9.12 para desenvolver o modelo econométrico explicativo para obter um melhor grau de explicação e previsão.Optou-se pelo Método dos Mínimos Quadrados Ordinários (MQO), primeiro, por ser um método simples, além de gerar resultados confiáveis, pois ele minimiza a soma dos quadrados dos resíduos, ou seja, a diferença entre o valor observado e o correspondente valor ajustado; segundo, mesmo este método não estando presente nos estudos destacados, analisando a bibliografia econométrica, foi considerado o mais adequado para o estudo que se pretende desenvolver. Assim, foi possível desenvolver o modelo de regressão nos formatos linear e logaritmo, propiciando a obtenção das elasticidades e semielasticidades, o que revelou a sensibilidade da variável dependente em relação às demais variáveis explicativas.

\subsection{Procedimentos metodológicos}

Para a análise da influência do modelo cooperativista no desenvolvimento local do município de Boa Vista do Sul, no período 1997-2010, as variáveis econômicas adotadas foram: 
a) Boa Vista do Sul:

- Valor Adicionado (VA) anual, em R\$ mil, utilizando-se a variável segmentada por setor: Agricultura, Indústria e Serviços;

- Produto Interno Bruto (PIB) do município anual, em R\$ mil. A fonte dos dados utilizada foi a base de dados da FEE;

b) Rio Grande do Sul: PIB anual, em $\mathrm{R} \$$ mil, dados obtidos na base de dados da FEE;

c) Brasil: PIB anual, em R $\$$ mil, obtido no IPEADATA, que é a base de dados do IPEA.

A Tabela 1 apresenta as séries históricas das variáveis econômicas que foram utilizadas para desenvolver o modelo de análise. O período observado do VA por setor (Agricultura, Indústria e Serviços), do PIB de Boa Vista do Sul, do PIB do Rio Grande do Sul e do PIB do Brasil compreende os anos de 1997 a 2010.

Tabela 1: Séries históricas das variáveis econômicas do modelo, em $\mathrm{R}$ mil

\begin{tabular}{c|c|c|c|c|c|c}
\hline Ano & VA Agricultura & VA Indústria & VA Serviços & $\begin{array}{c}\text { PIB Boa Vista } \\
\text { do Sul }\end{array}$ & $\begin{array}{c}\text { PIB Rio } \\
\text { Grande do Sul }\end{array}$ & PIB Brasil \\
\hline 1997 & 14.516 & 165 & 10.403 & 28.009 & 64.991 & 939.147 \\
1998 & 15.370 & 175 & 13.067 & 32.133 & 67.673 & 979.276 \\
1999 & 6.941 & 719 & 5.971 & 13.957 & 74.016 & 1.065 .000 \\
2000 & 7.190 & 949 & 6.305 & 14.823 & 81.815 & 1.179 .482 \\
2001 & 10.752 & 1.542 & 7.271 & 20.192 & 92.310 & 1.302 .136 \\
2002 & 13.037 & 2.169 & 8.095 & 24.074 & 105.487 & 1.477 .822 \\
2003 & 17.188 & 2.853 & 10.067 & 31.224 & 124.551 & 1.699 .948 \\
2004 & 13.375 & 3.458 & 9.853 & 28.113 & 137.831 & 1.941 .498 \\
2005 & 11.471 & 3.778 & 10.636 & 27.556 & 144.218 & 2.147 .239 \\
2006 & 14.462 & 4.046 & 11.731 & 31.793 & 156.827 & 2.369 .484 \\
2007 & 15.245 & 3.976 & 13.081 & 33.922 & 176.615 & 2.661 .344 \\
2008 & 12.583 & 4.224 & 13.790 & 32.596 & 199.494 & 3.032 .203 \\
2009 & 14.302 & 6.218 & 15.071 & 38.001 & 215.864 & 3.239 .404 \\
2010 & 26.155 & 9.063 & 22.468 & 61.184 & 252.483 & 3.770 .085 \\
\hline
\end{tabular}

Fonte: FEE ([2015e, 2015f, 2015g, 2015h, 2015i]); Instituto de Pesquisa Econômica Aplicada - IPEA (2015).

Ao analisar os dados das séries históricas apresentadas na Tabela 1, primeiramente, o VA dos setores da Agricultura, da Indústria e dos Serviços do município de Boa Vista do Sul, observa-se que a Agricultura e a Indústria apresentaram um crescimento modesto de, respectivamente, 5,88\% e 6,06\%, entre 1997 e 1998, sendo mais expressivo o setor de Serviços, com uma variação de $25,61 \%$. No ano seguinte, há uma queda significativa das variáveis Agricultura (-54,84\%) e Serviços (-54,30\%), porém, com uma expansão muito significativa da Indústria, com 310,85\%. A partir de 2000, todos os setores voltaram a crescer, 
mas apresentando maiores disparidades na trajetória. O setor de Serviços apresentou uma leve queda em 2004, se recuperando logo em 2005 e mantendo sua trajetória de crescimento até 2010, sendo que em relação ao ano anterior seu crescimento foi de 49,08\%. É importante destacar que as atividades do setor de Serviços estão diretamente atreladas ao setor da Agricultura. A Indústria apresentou uma expansão mais constante, tendo uma leve queda somente em 2007, mas já se recuperando no ano seguinte e mantendo seu crescimento até 2010, com uma variação de 45,75\% em relação ao ano de 2009. A Agricultura apresentou uma queda consecutiva nos anos de 2004 e 2005, se recuperando em 2006 e mantendo o crescimento em 2007, mas caindo novamente em 2008 e logo se recuperando em 2009 para quase dobrar seu valor adicionado em 2010, com um crescimento de 82,87\%. Dentre os fatores que impactaram as quedas do setor da Agricultura, destacam-se a desativação de aviários; a gripe aviária, impossibilitando o alojamento de aves; fechamento, fusão e troca de integradoras, o que também acarreta períodos sem alojamento; baixo preço do frango vivo; e falta de controle na digitação dos valores da produção primária. Nota-se que ao longo do período analisado os setores cresceram significativamente, com destaque para a Indústria devido à instalação de novas empresas. Esse movimento dos setores se reflete no PIB do município, sendo que sua trajetória é mais semelhante com a do valor adicionado da Agricultura, pois este é o setor que impulsiona a economia de Boa Vista do Sul. De acordo com a FEE (2012), o município esteve entre os 10 entes municipais que mais crescerem em 2010, com um percentual de 61\%, enquanto que no período de 1997 a 2010 sua expansão foi de 118,44\%. Quanto ao PIB do Rio Grande do Sul e do Brasil, ambos apresentaram uma trajetória de crescimento no período analisado, demonstrando um crescimento gradativo e semelhante de seus valores. Em 2010, o PIB do Rio Grande do Sul cresceu 16,96\% em relação ao seu PIB de 2009 e o PIB do Brasil apresentou um crescimento de 16,38\%, considerando o mesmo período. Relacionando o PIB de Boa Vista do Sul com os PIBs do estado e do país, observa-se que o PIB do município apresentou um crescimento bem mais expressivo nos dois últimos anos da análise.

O PIB, que é um dos indicadores mais utilizados na macroeconomia, foi adotado para mensurar a influência da cooperativa de crédito Sicredi Serrana RS, unidade de atendimento de Boa Vista do Sul, na atividade econômica do município. Em relação ao PIB do Rio Grande do Sul e ao PIB do Brasil, sua adoção teve o objetivo de verificar se houve ou não influência dessas variáveis no crescimento de Boa Vista do Sul. Com esse mesmo intuito, utilizou-se o 
VA municipal, mas fragmentado por setor, para identificar o quanto os setores econômicos estão envolvidos e são responsáveis pelo crescimento do município.

Visto que não foi possível obter dados consistentes da cooperativa de crédito em análise, a cooperativa passou a ser considerada uma variável dummy ou binária no modelo. De acordo com Matos (1995), é a variável que indica a ocorrência ou não de um evento ou a presença ou a ausência de uma condição. Geralmente, assume somente dois valores: 1 (um) quando indica uma situação e 0 (zero) quando se relaciona a outra. Nesse estudo, o valor 0 (zero) representou o período de 1997 a 2002, quando a cooperativa de crédito ainda não estava presente no município, e o valor 1 (um) referiu-se ao período de 2003 a 2010, quando a cooperativa de crédito já atuava na região. Assim, a variável dummy cooperativa buscou mostrar se a partir da instalação da cooperativa de crédito Sicredi Serrana RS, unidade de atendimento de Boa Vista do Sul, a mesma teve influência no crescimento do município.

A partir das variáveis mencionadas, o modelo compreendeu a investigação dos fatores determinantes do crescimento do município, sendo que estes foram dispostos da seguinte forma:

a) LPIB_BVS = PIB do município de Boa Vista do Sul no formato logarítmico;

b) $\alpha_{0}=$ Constante gerada automaticamente

c) agricultura = VA da Agricultura;

d) indústria = VA da Indústria;

e) serviços = VA dos Serviços;

f) PIB_RS = PIB do Rio Grande do Sul;

g) PIB_BR = PIB do Brasil;

h) cooperativa $=$ Variável binária, que assume valor $=0$ para o período de tempo em que a cooperativa não existia no município e valor $=1$ para o período de tempo em que a cooperativa passou a atuar no município.

i) $\varepsilon_{t}=$ Erro padrão.

A ideia de se utilizar a variável explicativa no formato logaritmo tem o objetivo de poder medir o comportamento das demais variáveis em termos percentuais. Assim, o modelo pode ser descrito a partir da equação 1:

$L P I B_{-} B V S=\alpha_{0}+\alpha_{1}$ Agric. $+\alpha_{2}$ Ind.$+\alpha_{3}$ Serv. $+\alpha_{4} P I B_{-} R S+\alpha_{5} P I B_{-} B R+\alpha_{6} C O O P+\varepsilon_{t}(1)$ 
A expectativa quanto às variáveis é que o crescimento da Agricultura, da Indústria, dosServiços, do PIB do Rio Grande do Sul, do PIB do Brasil e da cooperativa tenham sinal positivo; ou seja, quanto maior o crescimento dessas variáveis, tanto maior será o crescimento do município. Quanto ao erro padrão, segundo Gujarati (2006), se faz necessário para medir a confiabilidade ou precisão dos estimadores. Então, quanto menor for o valor do erro padrão, mais confiáveis ou precisos serão os estimadores do modelo.

Para a estimação do modelo utilizou-se o Método dos Mínimos Quadrados Ordinários (MQO), que, segundo Matos (1995), tem por objetivo obter estimativas dos parâmetros a partir de uma amostra dos valores das variáveis de modo que os erros e os resíduos sejam mínimos. No modelo, a variável dependente foi o PIB de Boa Vista do Sul e as variáveis explicativas foram a Agricultura, a Indústria, os Serviços, o PIB do Rio Grande do Sul, o PIB do Brasil e a Cooperativa. A Tabela 2 apresenta os dados estimados para todas as variáveis do modelo.

Tabela 2: Modelo de Regressão em MQO com seis variáveis

\begin{tabular}{c|c|c|c|c}
\hline \multicolumn{7}{c}{ Variável dependente: LPIB_BVS } \\
\hline Variáveis Explicativas & Coeficiente & Erro Padrão & Razão-t & P-valor \\
\hline Constante & 3,38181 & 0,239135 & 14,142 & $<0,00001$ \\
Agricultura & $-0,00012938$ & 0,0001009 & $-1,282$ & 0,24058 \\
Indústria & 0,00639786 & 0,00337253 & 1,8971 & 0,09964 \\
Serviços & 0,00402252 & 0,0033853 & 1,1882 & 0,27349 \\
PIB_RS & 0,00149134 & 0,00998381 & 0,1494 & 0,88547 \\
PIB_BRASIL & $4,5634 \mathrm{E}-05$ & 0,00903344 & 0,0051 & 0,99611 \\
Cooperativa & 0,178941 & 0,109373 & 1,6361 & 0,14584 \\
\hline
\end{tabular}

Fonte: Elaborado pelos autores a partir do software Gretl 1.9.12.

É importante destacar que os dados utilizados sofreram tratamento estatístico e alteração de base para $1997=100$. Para seleção das variáveis significativas para a análise, observou-se a coluna razão-t, onde quando o número é maior que dois em módulo, considerase que a variável é significativa para o modelo em $95 \%$ dos casos. Neste caso, nenhuma das variáveis se mostrou relevante. Mas, como o objetivo é verificar o grau de importância da cooperativa no crescimento do município, foram desconsideradas as variáveis exógenas ao local, o PIB gaúcho e o PIB brasileiro. Deve-se ressaltar que a retirada das variáveis ocorreu uma de cada vez, sendo que aquela que apresentasse o menor valor crítico, em módulo, foi retirada por primeiro. Assim, o modelo foi estimado novamente com as quatro variáveis 
consideradas endógenas ao local. Os resultados obtidos na segunda estimação do modelo podem ser observados na Tabela 3.

Tabela 3: Modelo de Regressão em MQO com quatro variáveis

\begin{tabular}{c|c|c|c|c}
\hline \multicolumn{7}{c}{ Variável dependente: LPIB_BVS } \\
\hline Variáveis Explicativas & Coeficiente & Erro Padrão & Razão-t & P-valor \\
\hline Constante & 3,53293 & 0,0925145 & 38,188 & $<0,00001$ \\
Agricultura & 0,00514317 & 0,001709 & 3,0095 & 0,01473 \\
Indústria & $-6,0541 \mathrm{E}-05$ & $4,0281 \mathrm{E}-05$ & $-1,503$ & 0,16709 \\
Serviços & 0,00522407 & 0,00169193 & 3,0876 & 0,01298 \\
Cooperativa & 0,228923 & 0,0822731 & 2,7825 & 0,02131 \\
\hline
\end{tabular}

Fonte: Elaborado pelos autores a partir do software Gretl 1.9.12.

Conforme a Tabela 3 demonstra, somente a Indústria não se apresentou significativa para o modelo, pois, além de seu coeficiente ser o de menor valor, ela é menor que dois em módulo. Assim, esta variável foi excluída e após estimou-se o modelo novamente, obtendo um novo modelo com todas as variáveis, sendo significativas. Portanto, das seis variáveis selecionadas, metade delas não se apresentaram significativas para explicar o crescimento de Boa Vista do Sul. As variáveis explicativas selecionadas para o modelo foram: Agricultura, Serviços e Cooperativa (dummy). A Tabela 4 apresenta o modelo que apresentou os resultados mais significativos, bem como os critérios utilizados.

Tabela 4: Critérios e Modelo de Regressão em MQO com três variáveis explicativas

\begin{tabular}{c|c|c|c|c}
\hline \multicolumn{5}{c}{ Variável dependente: LPIB_BVS } \\
\hline Variáveis Explicativas & Coeficiente & Erro Padrão & Razão-t & P-valor \\
\hline Constante & 3,59526 & 0,08775 & 40,9716 & $<0,00001$ \\
Agricultura & 0,00532688 & 0,00180875 & 2,9451 & 0,01466 \\
Serviços & 0,00386113 & 0,00151564 & 2,5475 & 0,02899 \\
Cooperativa & 0,149063 & 0,0666507 & 2,2365 & 0,0493 \\
\hline \multicolumn{5}{c}{ Critérios } \\
R & 0,95 & $\mathrm{R}^{2}$ ajustado & 0,93 \\
Critério de Schwarz & $-18,84$ & Critério de Akaike & $-21,40$ \\
Teste F (3, 10) & 57,43 & & \\
\hline
\end{tabular}

Fonte: Elaborado pelos autores a partir do software Gretl 1.9.12.

Para verificar se o modelo proposto se ajusta aos dados amostrais, foram analisados os critérios apresentados na Tabela 4. De acordo com Gujarati (2006), o $\mathrm{R}^{2}$ demonstra a qualidade de ajustamento de um modelo de regressão, ou seja, diz o quanto a linha de regressão amostral se ajusta aos dados. Em outras palavras, mede a proporção ou percentual 
da variação total da variável dependente, no caso o PIB de Boa Vista do Sul, explicada pelo modelo de regressão. Este se situa necessariamente entre 0 e 1, sendo que quanto mais próximo de 1 , melhor o ajustamento do modelo. O coeficiente $\mathrm{R}^{2}$ do modelo é de 0,95 , mostrando que a regressão ajustada explica 95\% da variação do PIB municipal. Entretanto, quando o $\mathrm{R}^{2}$ incorpora o aumento do número de variáveis explanatórias ou regressores ao modelo, quase invariavelmente sempre aumenta e nunca diminui. Diante disso, verifica-se o $\mathrm{R}^{2}$ ajustado que segue a mesma lógica do que o $\mathrm{R}^{2}$, porém quando o número de variáveis explanatórias aumenta, o $\mathrm{R}^{2}$ ajustado aumenta menos que o $\mathrm{R}^{2}$ não ajustado, sendo, portanto, uma medida de ajustamento melhor que a anterior (GUJARATI, 2006). Assim, o $\mathrm{R}^{2}$ ajustado apresentou coeficiente no valor de 0,93 , mostrando que a regressão ajustada explica $93 \%$ da variação do PIB de Boa Vista do Sul.

Os critérios de informação de Akaike e Schwarz também foram utilizados para avaliar a adequação do modelo de regressão proposto. $\mathrm{O}$ critério de informação de Akaike impõe uma pena mais dura que o $\mathrm{R}^{2}$ ajustado quando do acréscimo de regressores. Então, quanto menor o valor deste critério melhor será o modelo. O mesmo ocorre com o critério de informação de Schwarz, contudo, este é mais rigoroso que o anterior (GUJARATI, 2006).

O Teste F procura demonstrar se as variáveis do modelo estão inter-relacionadas, ou seja, se as variáveis independentes são significativas para a variável dependente. O valor crítico para $\mathrm{F}(3,10)$, a $1 \%$ de significância é de 6,55 , a $5 \%$ de significância é de 3,71 e a $10 \%$ de significância é de 2,73, então, sendo o valor calculadode 57,43 muito superior aos valores críticos, observa-se que a hipótese nula é aceita, ou seja, o modelo apresenta variáveis interrelacionadas significativamente, há significância conjunta das variáveis (GUJARATI, 2006). Assim, com as variáveis estatisticamente significativas identificadas, o modelo foi descrito pela equação 2:

$$
\begin{aligned}
& L P I B \_B V S=3,59526+0,00532688 \text { Agricultura }+0,00386113 \text { Serviços }+0,149063 \text { Coop }+0,100205 \text { عt } \\
& \begin{array}{llll}
(0,08775) & (0,00180875) & (0,00151564) & (0,0666507)
\end{array}
\end{aligned}
$$

O modelo demonstra que as variáveis selecionadas são todas significativas. Em primeiro lugar, pode-se avaliar que se todas as variáveis fossem nulas, ainda assim o crescimento médio de longo prazo do município seria da ordem de R \$3.595.000,00. Já em relação ao crescimento do setor Agrícola e do setor de Serviços, para cada 1,0\% de aumento no valor agregado nesses setores, os mesmos contribuem com 0,53\%, no caso da Agricultura, 
e $0,38 \%$, no caso dos Serviços, para o crescimento do município. Ou seja, os mesmos são significativos e influenciam no crescimento do município.

Já a variável binária, que representa a presença da cooperativa de crédito, apresentou o valor mais elevado em termos de coeficiente, com valor de 0,149063 , o que significa que a presença da cooperativa no município impulsiona o crescimento em 14,91\%. As razões para tal episódio podem estar relacionadas a um aumento da concentração tanto de poupança da população, o que leva uma oferta maior de recursos para investimento no próprio município, como um maior acesso a linhas de fomento, sejam essas na esfera federal ou estadual.

Quanto ao erro padrão, o mesmo apresentou coeficiente de 0,100205, demonstrando que os estimadores do modelo são precisos, sendo que quanto menor mais confiável é o modelo. Portanto, o modelo de estimativa de crescimento de Boa Vista do Sul é confiável, pois seu erro padrão é de apenas 10,02\%.

\subsubsection{Testes Estatísticos Aplicados ao Modelo}

Com o intuito de verificar se o modelo é adequado para análise, a raiz unitária de todas as variáveis foram testadas. Após a confirmação de que nenhuma das três explicativas do modelo: Agricultura, Serviços e Cooperativa, apresentaram problemas de raiz unitária, conforme pode ser visto no Apêndice A, foram realizados testes adicionais.

Contudo, é importante destacar que, há 1,0\% de significância, somente as variáveis PIB RS e PIB Brasil revelaram instabilidade, sendo que as demais não apresentaram problemas. Os testes aplicados foram divididos em quatro grupos.

O primeiro grupo de testes aplicado procurou verificar se havia ou não a presença de heterocedasticidade. De acordo com Gujarati (2006), uma premissa importante do modelo de regressão linear é que os termos de erro $u_{i}$ da função de regressão devem ser homocedásticos, isto é, devem ter todos a mesma variância. Quando isso não ocorre, portanto, afirma-se que há heterocedasticidade, ou seja, a variância dos resíduos não é constante, há dispersão dos erros. Para esta análise foram utilizados dois testes: Breusch-Pagan e White.

O teste de Breusch-Pagan para o modelo pressupõe que os resíduos apresentarão distribuição normal se a hipótese nula for aceita. O valor calculado para a estatística é 3,60706 e este resultado deve ser analisado com base na tabela Qui-Quadrado, utilizando 3 graus de liberdade. A partir disso, verificou-se se a estatística encontrada fica dentro do intervalo de confiança para os três níveis de significância: $1 \%, 5 \%$ e 10\%. Para $1 \%$ de significância, a tabela sugere o intervalo entre -11,34 e 11,34. A 5\% de significância, o intervalo é entre -7,81 
e 7,81. Por fim, com $10 \%$ de significância, -6,25 e 6,25. A conclusão obtida com o teste, a partir da evidência amostral, é que a estatística fica dentro dos três intervalos, portanto, logo se aceita a hipótese nula sem a presença de heterocedasticidade.

O resultado do Teste de White efetuado sobre o modelo quanto ao valor calculado para a estatística é de 11,9039 e este resultado deve ser analisado com base na tabela QuiQuadrado, utilizando 8 graus de liberdade. A partir disso, verificou-se se a estatística encontrada fica dentro do intervalo de confiança para os três níveis de significância: $1 \%, 5 \%$ e $10 \%$. Para $1 \%$ de significância, a tabela sugere o intervalo entre $-20,09$ e 20,09 . A $5 \%$ de significância, o intervalo é entre - 15,51 e 15,51. Por fim, com 10\% de significância, - 13,36 e 13,36. Estando o valor estimado de 11,9039 dentro dos intervalos sugeridos, com base na evidência amostral, se aceita a hipótese nula de não existência de heterocedasticidade.

Em ambos os testes, Breusch-Pagan e White, verificou-se que não ocorre heterocedasticidade, portanto, o modelo é homocedástico, pois à medida que oscila o valor das variáveis independentes, Agricultura, Serviços e Cooperativa, os resíduos permanecem constantes.

De acordo com Gujarati (2006), os modelos de regressão pressupõem que o termo de erro relacionado a qualquer das observações não é influenciado pelo termo de erro de qualquer outra observação. Ou seja, implica que o resíduo obtido no momento t não estaria correlacionado com o resíduo do momento $t+n, \ldots, t+2, t, t-1, t-2, \ldots, t-n$. Porém, é comum que exista uma relação nos resíduos de um modelo de regressão obtidos no momento $t$ com os resíduos da mesma regressão no momento $t$ - 1 . Esse comportamento é denominado de autocorrelação e procura verificar se existe influência do comportamento passado das variáveis sobre as mesmas no presente. Tem como pressuposto que os resíduos não estarão correlacionados se a hipótese nula for aceita.

A análise da presença ou ausência de autocorrelação compreende o segundo grupo de testes aplicado ao modelo proposto. Para o cálculo do teste foi admitida apenas uma defasagem, ou seja, até a ordem 1. A estatística encontrada foi de 0,00314409 com 1 grau de liberdade e tamanho da amostra 9. De acordo com a Tabela F de Snedecor, os intervalos de significância se encontram entre -10,56 e 10,56 para 1\%, -5,12 e 5,12, para 5\%, e -3,36 e 3,36, para $10 \%$. Assim, a estatística calculada fica dentro dos intervalos, logo se aceita a hipótese nula e admite-se que não existe autocorrelação entre os resíduos, de acordo com a evidência amostral. 
Para confirmar o resultado do teste anterior, aplicou-se o Teste de Durbin-Watson. É importante destacar que o teste examina somente a existência de correlação de primeira ordem. Portanto, de acordo com Gujarati (2006), a regra básica é ao verificar em uma aplicação que $d$ é menor que 2, pode-se pressupor que não há autocorrelação de primeira ordem, seja positiva ou negativa. Assim, a estatística encontrada de 1,660529 demonstra que não existe autocorrelação nos resíduos.

Modelos de regressão assumem a hipótese de que os coeficientes estimados são constantes ao longo do tempo. Ou seja, assume-se que os dados são estacionários. Ao utilizar um modelo de regressão que envolve o uso de séries temporais, pode acontecer de ocorrer uma mudança estrutural na série de dados. Essa mudança estrutural, segundo Gujarati (2006), refere-se aos valores dos parâmetros do modelo não se manterem idênticos durante todo o período de análise.

O terceiro grupo de testes busca verificar a presença de quebra estrutural nos dados observados. A série temporal em análise, que vai de 1997 a 2010, foi dividida em duas, sendo o primeiro intervalo de 1997 a 2002 e o outro de 2003 a 2010. Isso porque 2003 foi o ano em que a cooperativa de crédito Sicredi Serrana RS, unidade de atendimento de Boa Vista do Sul, se instalou no município de Boa Vista do Sul. Tal divisão foi feita para que fosse possível aplicar o Teste de Chow, que procura revelar se existem quebras estruturais no comportamento da série. Já a hipótese nula indica que não há quebras estruturais da série. A estatística encontrada é de 70,8527, sendo que este resultado deve ser analisado com base na Tabela F de Snedecor, com 2 graus de liberdade e 8 como tamanho da amostra. A Tabela sugere a $1 \%$ de significância, o intervalo de confiança entre $-8,65$ e 8,65, para 5\% de significância, o intervalo entre $-4,46$ e 4,46 e, para $10 \%$ de significância, o intervalo é entre $-3,11$ e 3,11. Percebe-se que o cálculo da estatística fica fora dos intervalos de confiança, demonstrando que é estatisticamente significativo, pois a hipótese nula é rejeitada. Assim, conclui-se que há uma mudança estrutural na série de dados, ou seja, como o teste quebra a série de dados ao meio ele evidencia que existe uma diferença no crescimento do município ao longo do tempo.

Outra premissa importante em modelos de regressão, segundo Gujarati (2006), é a normalidade do termo de erro ui. Ou seja, o termo de erro tem que seguir uma distribuição normal. Caso contrário, o procedimento de teste não será válido. Assim, o último grupo de testes tem por finalidade verificar se os resíduos estão normalmente distribuídos em torno de sua média. Sob a hipótese de normalidade admite-se que a média é igual à mediana e 
também igual à moda, ou seja, os dados são distribuídos de forma simétrica. Portanto, na ausência de normalidade, os dados podem apresentar assimetria. Para as conclusões deste grupo, analisou-se o gráfico de distribuição dos erros e realizou-se teste de normalidade dos resíduos. Através do Gráfico 1 percebe-se indícios de que os resíduos apresentam distribuição normal.

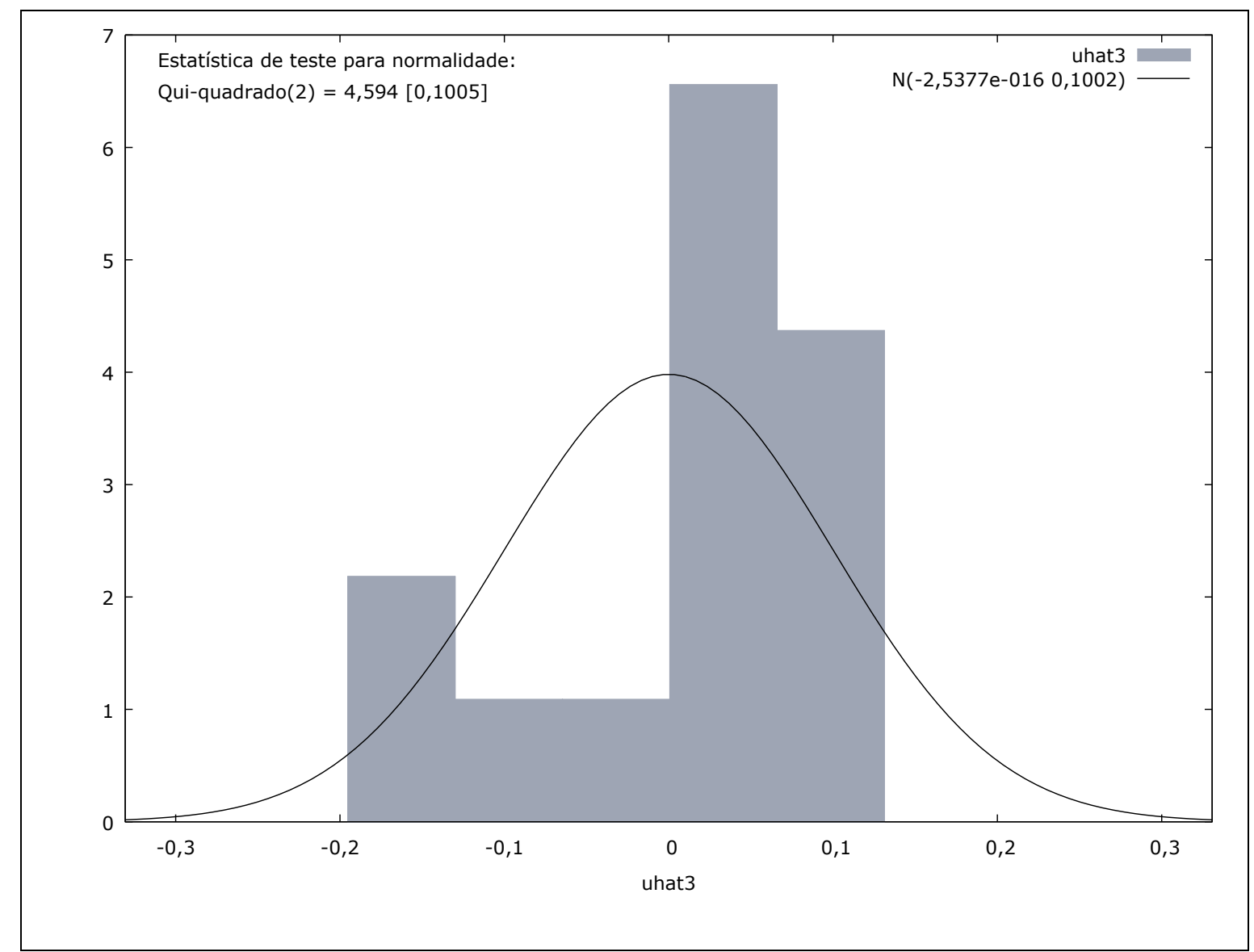

Gráfico 1: Teste de Normalidade dos Resíduos

Fonte: Elaborado pelos autores a partir do software Gretl 1.9.12.

Para confirmação foi aplicado o Teste de Normalidade, que exige que seja feita a análise do valor estimado com base na tabela Qui-Quadrado com 2 graus de liberdade. A partir disso verificou-se se a estatística encontrada fica dentro do intervalo de confiança para os três níveis de significância: $1 \%, 5 \%$ e $10 \%$. Para $1 \%$ de significância, a tabela sugere o intervalo entre -9,21 e 9,21. A 5\% de significância, o intervalo é entre - 5,99 e 5,99. Por fim, com $10 \%$ de significância, - 4,61 e 4,61. Portanto, estando o valor estimado de 0,100544 dentro dos intervalos sugeridos, com base na evidência amostral, se aceita a hipótese nula com distribuição normal dos resíduos. 
A Tabela 5 apresenta o resumo dos resultados obtidos nos testes estatísticos aplicados ao modelo.

Tabela 5: Resumo dos resultados dos testes estatísticos aplicados ao modelo

\begin{tabular}{c|c|c}
\hline Teste & Estatística & Hipótese Nula \\
\hline Teste de Breusch-Pagan & 3,60706 & Aceita para $1 \%, 5 \%$ e $10 \%$. \\
Teste de White & 11,9039 & Aceita para $1 \%, 5 \%$ e $10 \%$. \\
Autocorrelação & 0,0031441 & Aceita para $1 \%, 5 \%$ e $10 \%$. \\
Teste de Durbin-Watson & 1,660529 & Aceita. \\
Teste de Chow & 70,8527 & Rejeita para $1 \%, 5 \%$ e $10 \%$. \\
Teste de Normalidade & 0,100544 & Aceita para $1 \%, 5 \%$ e $10 \%$. \\
\hline
\end{tabular}

Fonte: Elaborado pelos autores a partir do software Gretl 1.9.12.

Como pode ser observado, todos os testes aplicados ao modelo obtiveram o resultado esperado nas análises, demonstrando que o modelo é adequado para explicar o crescimento de Boa Vista do Sul.

\subsubsection{Elasticidades do Modelo Proposto}

A elasticidade é utilizada para verificar o quanto uma variável é ou não sensível a determinado fator. Mais especificamente, segundo Pindyck e Rubinfeld (2010), é um número que informa a variação percentual que ocorrerá em uma variável como reação a um aumento de um ponto percentual em outra variável. Economicamente, Garófalo e Carvalho (1976) afirmam que a elasticidade expressa uma relação entre duas variáveis funcionalmente inter-relacionadas. Este método de análise foi utilizado para o modelo proposto a fim de verificar o quanto a variável LPIB_BVS é influenciada pelo comportamento das variáveis explicativas. Assim, a equação inicial 1 sofreu alteração na forma de apresentação dos parâmetros, passando de $\alpha$ para $\beta$, obtendo uma nova forma de acordo com a ilustração da equação 3:

$$
L P I B_{-} B V S=\beta_{0}+\beta_{1} \text { Agric. }+\beta_{2} \text { Ind. }+\beta_{3} \text { Serv. }+\beta_{4} P I B+R S+\beta_{5} P I B \_B R+\beta_{6} C O O P+\varepsilon_{t}(3)
$$

Todas as variáveis foram transformadas para valores em logaritmos, gerando um modelo log-log, exceto a dummy Cooperativa. Tal procedimento torna possível medir a elasticidade e as semi-elasticidades das variáveis. Assim, conforme Pindyck e Rubinfeld (2010), quando a elasticidade é superior a 1 em magnitude, significa que ela é elástica. E quando a elasticidade for menor que 1 em magnitude, significa que ela é inelástica. A Tabela 6 apresenta as elasticidades das variáveis explicativas do modelo. 
Tabela 6: Elasticidades das variáveis explicativas do Modelo de Regressão em MQO para o PIB de Boa Vista do Sul

\begin{tabular}{c|c|c|c|c}
\hline \multicolumn{5}{c}{ Variável dependente: LPIB_BVS } \\
\hline Variáveis Explicativas & Coeficiente & Erro Padrão & Razão-t & P-valor \\
\hline Constante & $-0,240041$ & 0,11553 & $-2,0777$ & 0,06444 \\
L_Agricultura & 0,493905 & 0,0420973 & 11,7325 & $<0,00001$ \\
L_Serviços & 0,558697 & 0,0437954 & 12,757 & $<0,00001$ \\
Cooperativa & 0,0649114 & 0,0180381 & 3,5986 & 0,00486 \\
\hline
\end{tabular}

Fonte: Elaborado pelos autores a partir do software Gretl 1.9.12.

Com base nos dados demonstrados na Tabela 6, observa-se que todas as variáveis explicativas do modelo apresentam coeficiente de elasticidade menor que um, portanto, estas são inelásticas. Assim, o crescimento do PIB boavistense é sensível 0,49\% a Agricultura, 0,55\% ao Serviços e 0,06\% a Cooperativa. Isso significa que, de acordo com as evidências do modelo, a influência das variáveis explicativas será constante ao longo do tempo, sem se deixar influenciar por outros fatores.

\subsection{Análise e discussão dos resultados}

Com todos os testes aplicados, parte-se para a análise dos resultados obtidos. Mas, primeiramente, faz-se necessário destacar alguns aspectos respeitáveis. Primeiro, metade das variáveis selecionadas para o modelo inicial não foram consideradas significativas, sendo somente as variáveis Agricultura, Serviços e Cooperativa consideradas na análise. Das variáveis que foram rejeitadas, duas são de caráter exógeno ao município, o PIB do Rio Grande do Sul e o PIB do Brasil, e uma é de caráter endógeno ao local, a Indústria. Segundo, o $\mathrm{R}^{2}$ ajustado do modelo demonstra que em $93 \%$ dos casos, o modelo está ajustado para explicar o crescimento de Boa Vista do Sul. Terceiro, a constante do modelo apresentou-se estatisticamente relevante. Assim, o coeficiente estimado é de 3,59526, indicando que, caso todas as outras variáveis do modelo sejam iguais à zero, o crescimento do município ainda seria da ordem de R \$ 3.590.000,00. Quarto, o Teste de Chow mostrou-se estatisticamente relevante, pois ao rejeitar a hipótese nula de não existência de quebra estrutural na série de dados, o teste evidencia que, a partir do ano em que a cooperativa de crédito se instalou no município, os valores dos parâmetros do modelo não se mantiveram os mesmos.

Antes de analisar os resultados individuais de cada variável sobre o PIB de Boa Vista do Sul, vale ressaltar que todas as variáveis significativas do modelo apresentaram coeficientes com sinal idêntico ao esperado quando da proposição do modelo. Ou seja, as variáveis Agricultura, Serviços e Cooperativa apresentaram sinal positivo, demonstrando sua 
relação direta com o crescimento do município. A Tabela 7 apresenta os resultados da regressão em forma de equação:

Tabela 7: Equação resultante da regressão do modelo e Critérios

\begin{tabular}{|c|c|c|c|}
\hline $\begin{array}{c}\text { LPIB_BVS }=3,59526+0,0 \\
(0,08775) \\
\text { (Erros padrão abaixo de cad }\end{array}$ & $\begin{array}{l}\text { c. }+0,00 \\
\text { re parênt }\end{array}$ & $\begin{array}{c}0,149063 \text { Coop }+0 \\
(0,0666507)\end{array}$ & \\
\hline & & & \\
\hline $\mathrm{R}^{2}$ & 0,95 & $\mathrm{R}^{2}$ ajustado & 0,93 \\
\hline Critério de Schwarz & $-18,84$ & Critério de Akaike & $-21,40$ \\
\hline Teste F $(3,10)$ & 57,43 & & \\
\hline
\end{tabular}

Fonte: Elaborado pelos autores a partir do software Gretl 1.9.12.

Após as considerações iniciais do modelo, parte-se para a explicação de cada variável explicativa individualmente. A primeira variável a ser destacada é a Agricultura, que apresentou sinal positivo em seu coeficiente conforme esperado no planejamento do modelo. O coeficiente de 0,00532688 indica que a cada variação de 1\% na Agricultura, o PIB de Boa Vista do Sul tende a aumentar em $0,53 \%$ do seu valor.

O Gráfico 2 apresenta a relação entre o crescimento do VA da Agricultura e o PIB de Boa Vista do Sul entre 1997 e 2010. Observa-se que a Agricultura é expressiva em todo o período de análise e acompanha o crescimento do PIB municipal em curva ascendente. De acordo com Pereira et al. (2012), essa grande participação deve-se ao fato de a economia do município estar baseada no setor agropecuário, como a agricultura familiar que cultiva batata, uva, cebola, milho, tomate etc. Além da criação de suínos, gado leiteiro, a produção de ovos e, principalmente, a avicultura, com a criação de aves para abate. Contudo, é a avicultura que mais se destaca, colocando o município como um dos maiores produtores de frango de corte do estado, sendo o setor que impulsiona a economia. Com início na década de 1980, além de contribuir para o crescimento econômico da cidade, este setor é responsável por importantes mudanças socioeconômicas, como nível de empregabilidade, pois além dos integrantes das famílias é necessário contratar empregados que auxiliem na produção. Consequentemente, ocorre um aumento na renda per capita e no nível de instrução dos moradores. 


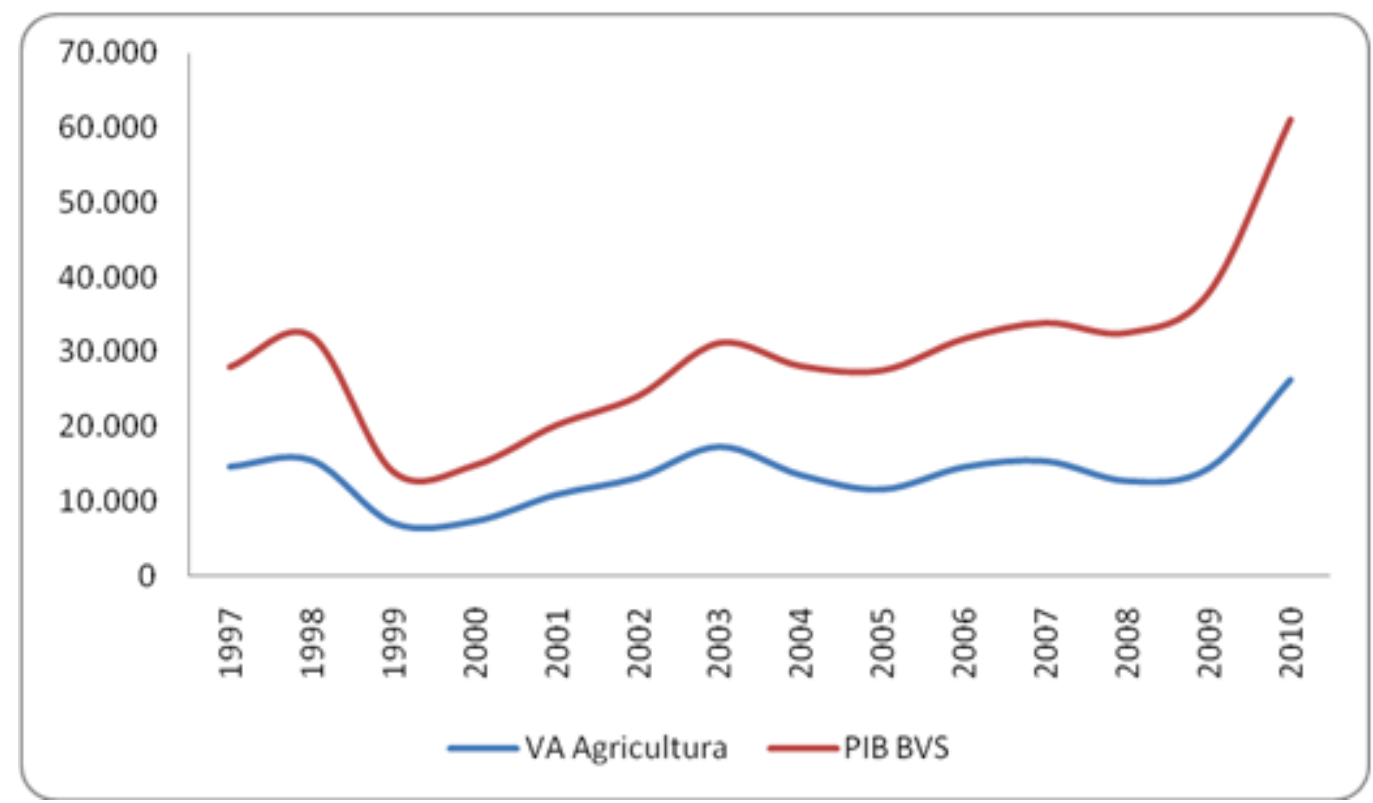

Gráfico 2: Valor Adicionado da Agricultura e PIB de Boa Vista do Sul, em R \$ mil, no período de 1997-2010

Fonte: Elaborado pelos autores a partir de FEE (2015e, 2015f, 2015g).

A segunda variável explicativa do modelo é o VA dos Serviços. Esta, de acordo com a proposição inicial, apresentou coeficiente positivo no valor de 0,00386113 demonstrando que a cada variação de $1 \%$ nos Serviços, o PIB boavistense tende a aumentar em 0,38\% do seu valor.

Uma questão importante a ressaltar é que as atividades do setor de Serviços estão diretamente atreladas ao setor da Agricultura, sendo este o setor dinâmico do município, a semelhança de seus coeficientes na impulsão do crescimento do PIB do município se justifica. Atividades como transporte e comércio de produtos agrícolas, principalmente, batata e cebola, devem ser destacadas, pois, além da existência de produtores que cultivam estas culturas, há atacados que fazem toda a parte logística do negócio. No setor avícola, a empresa Carrer Alimentos Ltda., além de atuar industrialmente no abate de aves, agrega no setor de Serviços quanto à importação e exportação dos produtos desenvolvidos (PEREIRA et al., 2012). Observa-se no Gráfico 3, o VA dos Serviços em relação ao PIB de Boa Vista do Sul no período de 1997 a 2010. O crescimento das duas variáveis é semelhante durante todo o período de análise, sendo que o setor de Serviços apresenta um crescimento mais constante. 


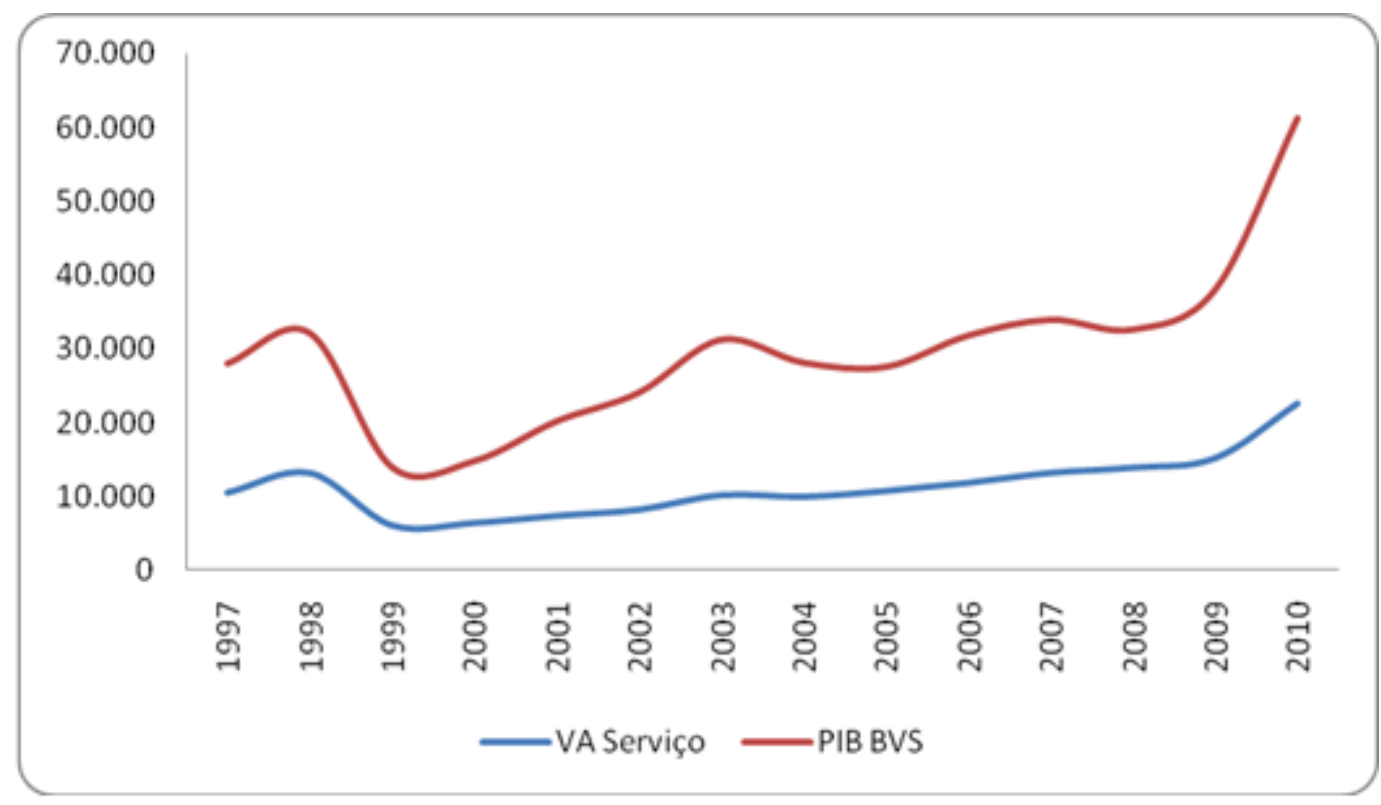

Gráfico 3: Valor Adicionado dos Serviços e PIB de Boa Vista do Sul, em R\$ mil, no período de 1997-2010

Fonte: Elaborado pelos autores a partir de FEE (2015e, 2015f, 2015g).

A última variável considerada significativa para o modelo é a dummy Cooperativa. A mesma apresenta coeficiente positivo, de acordo com as expectativas iniciais para esta variável, no valor de 0,149063 . Ou seja, a cooperativa contribui em $14,91 \%$ para o crescimento do PIB de Boa Vista do Sul.

Assim, a partir das evidências do modelo, a hipótese inicial proposta por este estudo de que a cooperativa de crédito Sicredi Serrana RS, unidade de atendimento de Boa Vista do Sul, contribuiu para o desenvolvimento socioeconômico do município é comprovada. Seu coeficiente se apresenta expressivo se considerar o tempo de atuação da mesma no município, apenas 10 anos. Contudo, deve-se destacar que a cooperativa de crédito se caracteriza como uma prestadora de serviços no município, portanto sua contribuição também é evidenciada através do crescimento do setor secundário, discutido anteriormente.

A principal atividade da mesma é a oferta de crédito, sendo que um dos recursos é a poupança, utilizada para investimentos dentro da própria região, ocorrendo a reciclagem dos recursos locais (FONSECA et al., 2009). Assim como Meinen e Port (2012) afirmam, as cooperativas não destinam seus recursos para fora da comunidade em que estão inseridas, pelo contrário, os recursos são reinvestidos no próprio local, pois elas respeitam os limites geográficos do município.

Deste modo, justifica-se o coeficiente de $14,91 \%$ na contribuição do crescimento do município de Boa Vista do Sul. Assim, como Fonseca et al. (2009) demonstram em seu 
estudo, é notória a participação da cooperativa de crédito, que devolve grande parte dos recursos depositados para seus locais de origem sob a forma de operações de crédito, contribuindo para o desenvolvimento regional.

Ao atender a dimensão econômica, já que é uma empresa voltada para os seus associados, oferecendo produtos e serviços de acordo com suas necessidades, também atende a dimensão social (RECH, 2000). Isto se justifica porque ao contribuir para o crescimento do município, a cooperativa de crédito em análise também auxiliou na melhora do bem estar da comunidade. Desde sua implantação, o número de associados só tem aumentado, promovendo, assim, a aproximação e a interação dos agentes no ambiente em que estão inseridos (SILVA et al., 2006). Como o processo de desenvolvimento local endógeno é promotor do dinamismo econômico e da melhoria da qualidade de vida da população (BUARQUE, 2002), a cooperativa de crédito Sicredi Serrana RS, unidade de atendimento de Boa Vista do Sul, se caracteriza como um agente endógeno na promoção do desenvolvimento local. Conforme Jesus (2003) afirma, o processo de desenvolvimento local mobiliza pessoas e instituições, buscando a transformação da economia e da sociedade local.

\section{Considerações Finais}

O estudo permitiu constatar a influência que o cooperativismo de crédito tem no desenvolvimento regional, sendo considerado um modelo econômico e social de organização que não faz distinção entre as classes sociais, culturas e religiões e que busca, primeiramente, o bem estar de seus cooperados. Conclui-se que as cooperativas de crédito têm um papel de destaque na promoção do desenvolvimento regional, sendo consideradas um fator endógeno de impulsão de crescimento, pois a sociedade local participa, já que as pessoas se organizam em torno de interesses em comum. Além disso, realocam os recursos na mesma região, melhorando a qualidade de vida da área de abrangência. Em suma, cumpre sua missão de "[...] corrigir o social através do econômico", conforme afirma Rodrigues (2012, p. 10), embaixador especial da Food and Agriculture Organization (FAO) e da ONU para o Cooperativismo Mundial.

Como parte do primeiro objetivo específico, é importante destacar as principais referências teóricas do desenvolvimento regional. Inicialmente, Lima e Oliveira (2003) ressaltam que o desenvolvimento pode resultar de iniciativas exógenas ou endógenas à região, sendo este último conhecido também como paradigma "desde baixo". Jesus (2003) afirma que o desenvolvimento local conceitua-se num processo que mobiliza as pessoas, pois precisam 
ser ouvidas para, assim, haver uma melhora nas condições de vida da comunidade. Nesse contexto, Buarque (2002) alega que a cooperação é fundamental para a construção do desenvolvimento do lugar. Por fim, conforme Frantz (2003) destaca, o cooperativismo, além de compreender os interesses e necessidades frente à produção e distribuição de bens e riquezas, engloba elementos sociais, culturais e políticos.

Em relação ao objetivo principal do estudo, por meio da estimação do modelo, os resultados apontados comprovam que a cooperativa de crédito Sicredi Serrana RS, unidade de atendimento - Boa Vista do Sul, contribuiuefetivamente para o desenvolvimento socioeconômico do município de Boa Vista do Sul em 14,91\%, a partir de 2003, ano de sua instalação.

Muitas razões colaboram para evidenciar este resultado. Uma delas é devido ao município estar mais voltado para a agricultura familiar, onde as famílias plantam para consumo próprio e o excedente é comercializado em municípios próximos. Para isso, os agricultores recorrem à cooperativa de crédito para efetivar empréstimos e financiamentos que auxiliem na compra de insumos, capital de giro, aquisição de máquinas e equipamentos, no intuito de aumentar a produtividade, sendo que nestas modalidades a de juros e inferior em relação aos bancos comerciais. Além de recursos próprios, a cooperativa de crédito repassa aos associados, linhas de financiamento oriundos dos programas do governo, como o custeio agrícola e o Programa Nacional de Financiamento Agrícola Familiar (Pronaf).

Conforme já destacado, a avicultura é o setor que maispropulsiona o município economicamente. Assim, os avicultores também buscam os recursos na cooperativa de crédito, seja no ensejo de ampliar a produção seja para se adequarem às normas produtivas exigidas pelas empresas de abate. Outro serviço oferecido pela cooperativa, em parceria com os avicultores é o recebimento dos honorários oriundos das empresas que manufaturam o frango criado nas propriedades da agricultura familiar. Este convênio faz com que haja contribuição por parte do produtor para a receita da cooperativa de crédito.

Outro aspecto relevante a se destacar é que não somente os agricultores e avicultores podem usufruir dos serviços oferecidos pela cooperativa, mas a população em geral, fazendo com que a mesma tenha maior solidez em termos de capital social. Conformea movimentação financeira que o associado realizar anualmente, irá receber proporcionalmente as sobras líquidas da cooperativa no final deste período. Portanto, quanto mais o associado se fidelizar à cooperativa, mais excedente irá receber e, consequentemente, mais sólida a cooperativa se tornará. Isso proporciona uma redução no preço final pago pelos cooperados e o aumento de 
remuneração de seus investimentos. Além disso, é importante destacar que parte do capital empregado nos empréstimos, quando não se origina das linhas do governo, tem como fonte o capital social e a poupança.

Como a unidade de atendimento de Boa Vista do Sul se localiza na sede do município e, mesmo tendo sua matriz localizada no município vizinho de Carlos Barbosa, presta contas à Prefeitura Municipal em termos de impostos. Portanto, quanto mais operações financeiras os associados realizarem na cooperativa de crédito, maior a contribuição mensal de retorno de impostos ao município. Os impostos recolhidos pela cooperativa são investidos totalmente para a população local, mostrando que a mesma além de contribuir para o crescimento econômico faz sua parte nademanda social, que é um de seus focos. Diferentemente é a prática da única instituição financeira "concorrente", o Banco do Estado do Rio Grande do Sul S/A (BANRISUL), que estando fixado no município, seus impostos são todos destinadosa sua agencia de origem Garibaldi, por compreenderem ser apenas um posto de atendimento e não uma agência local.

Ainda na questão social, deve-se ressaltar que a cooperativa de crédito contribui para a geração de empregos no município, onde cinco dos seis colaboradores que atuam na unidade são moradores de Boa Vista do Sul. Isso se torna um diferencial importante conforme Bertossoet al. (2008) destacam em seu estudo.

Por fim, como as cooperativas de crédito prezam os limites geográficos, ocorre uma reciclagem dos recursos nas próprias comunidades. Quanto maior for a concentração de poupança, maior será a oferta de recursos para investimento no próprio município. Isso contribui para o desenvolvimento local nos âmbitos econômico e social, assim como Franz (2006) concluiu a respeito das contribuições das cooperativas de crédito.

Quanto à variável Agricultura, esta apresentou que para cada 1,0\% de aumento no valor agregado deste setor seu comportamento é de $0,53 \%$, sendo significativa e contribuindo para o crescimento do PIB do município. De outra parte, a variável Serviços também contribuiu para o crescimento da economia do município, sendo que para cada $1,0 \%$ de aumento o seu comportamento é de 0,38\%. Assim, inserida no setor de Serviços, a cooperativa de crédito é um agente que atua no suporte para que isso aconteça. De acordo com FEE (2012), no ano de 2010, o município de Boa Vista do Sul esteve entre os 10 municípios com maior crescimento do Estado.

Indica-se, para estudos futuros, que seja feita uma análise da oferta de crédito da cooperativa em questão, pois a partir dessa variável é possível verificar, de forma mais 
aprofundada, a participação e a influência de uma cooperativa no desenvolvimento de uma região. Além disso, sugere-se uma pesquisa voltada para os associados, para verificar o grau de importância econômica da cooperativa de crédito no local de abrangência.

\section{Referências}

ANNIBAL, Clodoaldo Aparecido; KOYAMA, Sérgio Mikio. Cooperativas de crédito: taxas de juros praticadas e fatores de viabilidade. Brasília, DF: Banco Central do Brasil, nov. 2011. (Trabalhos para discussão, n. 257). Disponível em: <www.bcb.gov.br/pec/wps/port/td257.pdf>. Acesso em: 07 set. 2012.

BERTOSSO, Márcia Antônio et al. A percepção dos diferenciais cooperativos no cooperativismo de crédito. In: SIMPÓSIO DE EXCELÊNCIA EM GESTÃO E TECNOLOGIA - SEGeT, 5., 2008, Rezende, RJ. Gestão e tecnologia em tempos de competitividade. Rezende: AEDB, 2008. Disponível em:

$<$ http://www.aedb.br/seget/arquivos/artigos08/247_247_SEGET_2008_-

_Projeto_III_Geracao.pdf >. Acesso em: 11 mar. 2013.

BIALOSKORSKI NETO, Sigismundo. Estratégias e cooperativas agropecuárias: um ensaio analítico. In: BRAGA, Marcelo José; REIS, Brício dos Santos (Org.). Agronegócio cooperativo- reestruturação e estratégias. Viçosa, MG: Universidade Federal de Viçosa, 2002.p. 77-97.

BOESCHE, Leonardo. Fidelidade cooperativa: uma abordagem prática. Curitiba: SESCOOP/PR, 2005.

BUARQUE, Sergio Cavalcante. Construindo o desenvolvimento local sustentável: metodologia de planejamento. Rio de Janeiro: Garamond, 2002.

FONSECA, Reinaldo Aparecida et al. A importância das cooperativas de crédito como agentes de desenvolvimento regional: um estudo na SICOOB CREDICAMPO. 2009. Trabalho apresentado ao6 ${ }^{\circ}$ Congresso Virtual Brasileiro de Administração, São Paulo, 2009. Disponível em: <http://www.convibra.com.br/2009/artigos/198_0.pdf >. Acesso em: 02 abr. 2013.

FRANTZ, Walter. Caminhos para o desenvolvimento pelo cooperativismo. Ijuí: Ed. UNIJUÍ, 2003.

FRANZ, Cristiane Mesquita. A contribuição do cooperativismo de crédito para a eficiência econômica e eficácia social. 2006. 35 f. Trabalho de Conclusão de Curso (Graduação em Direito) - Faculdade de Direito, Pontifícia Universidade Católica do Rio Grande do Sul, Porto Alegre, RS, 2006. Disponível em:

$<$ http://www3.pucrs.br/pucrs/files/uni/poa/direito/graduacao/tcc/tcc2/trabalhos2006_2/cristian e.pdf> Acesso em: 04 mar. 2013.

FUNDAÇÃO DE ECONOMIA E ESTATÍSTICA (FEE). PIB municipal RS: 2010. Porto Alegre, 2012. Disponível em: <http://www.fee.rs.gov.br/pib/pib-municipal-rs-2010/>. Acessado em: 08 ago. 2014. 
FUNDAÇÃO DE ECONOMIA E ESTATÍSTICA (FEE). COREDE Serra. Porto Alegre, [2015a]. Disponível em: < http://www.fee.rs.gov.br/perfil-

socioeconomico/coredes/detalhe/?corede=Serra $>$. Acesso em: 11 jun. 2015.

FUNDAÇÃO DE ECONOMIA E ESTATÍSTICA (FEE). Índice de Desenvolvimento

Socioeconômico (Idese) dos Coredes do Rio Grande do Sul: 2013. Porto Alegre, [2015b].

(Série Histórica Nova Metodologia). Disponível em:

$<$ http://www.fee.rs.gov.br/indicadores/indice-de-desenvolvimento-socioeconomico/seriehistorica-nova-metodologia/ unidade $=$ coredes $\& a n o=2013 \& l e t r a=\&$ ordem $=$ saude $>$. Acesso em: 11 jun. 2015.

FUNDAÇÃO DE ECONOMIA E ESTATÍSTICA (FEE). Município: Boa Vista do Sul. Porto Alegre, [2015c]. Disponível em: <http://www.fee.rs.gov.br/perfilsocioeconomico/municipios/detalhe/?municipio=Boa+Vista+do+Sul $>$. Acesso em: 11 jun. 2015.

FUNDAÇÃO DE ECONOMIA E ESTATÍSTICA (FEE). Índice de desenvolvimento socioeconômico (Idese) dos municípios do Rio Grande do Sul: 2012.Porto Alegre, [2015d]. (Série Histórica Nova Metodologia).Disponível em:

$<$ http://www.fee.rs.gov.br/indicadores/indice-de-desenvolvimento-socioeconomico/seriehistorica-nova-metodologia/?ano=2012\&letra=B\&ordem=municipios $>$. Acesso em: 11 jun. 2015.

FUNDAÇÃO DE ECONOMIA E ESTATÍSTICA (FEE). PIB municipal: série histórica 2010-2013. Porto Alegre, [2015e]. Disponível em: <http://www.fee.rs.gov.br/indicadores/pibrs/municipal/serie-historica/>. Acesso em: 18 jun. 2015.

FUNDAÇÃO DE ECONOMIA E ESTATÍSTICA (FEE). PIB municipal: série histórica 1999-2009. Porto Alegre, [2015f]. Disponível em: <http://www.fee.rs.gov.br/indicadores/pibrs/municipal/serie-historica/>. Acesso em: 18 jun. 2015.

FUNDAÇÃO DE ECONOMIA E ESTATÍSTICA (FEE). PIB municipal: série histórica 1985-1998. Porto Alegre, [2015g]. Disponível em: <http://www.fee.rs.gov.br/indicadores/pibrs/municipal/serie-historica/>. Acesso em: 18 jun. 2015.

FUNDAÇÃO DE ECONOMIA E ESTATÍSTICA - FEE. PIB-RS: 2010-2013. Porto Alegre, [2015h]. Disponível em: <http://www.fee.rs.gov.br/indicadores/pib-rs/estadual/seriehistorica/>. Acesso em: 18 jun. 2015.

FUNDAÇÃO DE ECONOMIA E ESTATÍSTICA - FEE. PIB-RS: 1995-2010. Porto Alegre, [2015i]. Disponível em: <http://www.fee.rs.gov.br/indicadores/pib-rs/estadual/seriehistorica/>. Acesso em: 18 jun. 2015.

GARÓFALO, Gilson de Lima; CARVALHO, Luiz Carlos Pereira. Teoria do consumidor e análise da procura. São Paulo: Atlas, 1976.

GUJARATI, Damodar N. Econometria básica. Rio de Janeiro: Elsevier: Campos, 2006. INSTITUTO DE PESQUISA ECONÔMICA APLICADA (IPEA). Séries mais usadas: PIB. Brasília, DF, 2015. Disponível em: <http://www.ipeadata.gov.br/>. Acesso em: 18 jun. 2015. 
JESUS, Paulo de. Desenvolvimento local. In: CATTANI, Antonio David (Org.). A outra economia. Porto Alegre: Veraz, 2003. p. 72-75.

LIMA, José Edmilson de Souza; OLIVEIRA, Gilson Batista de. Elementos endógenos do desenvolvimento regional. Revista da FAE, Curitiba, v.6, n.1, p. 29-37, maio/dez. 2003.

LUCIAN, Mauro. Boa Vista do Sul na ponta do lápis. Porto Alegre: EST Edições, 2003.

MACHADO, Vanessa Dorneles Ribeiro; SCHMIDT, Derli. A inserção das Cooperativas de Crédito no Sistema Financeiro Nacional. Colóquio: revista científica da FACCAT, Taquara, v. 9, n. 1, p. 79-90, jan./jun. 2012. Disponível em:

<http://www.faccat.br/download/pdf/coloquio/9/a_insercao.pdf>. Acesso em: 02 abr. 2013.

MATOS, Orlando Carneiro de. Econometria básica: teoria e aplicações. São Paulo: Atlas, 1995.

MEINEN, Ênio; PORT, Márcio. O cooperativismo de crédito: ontem, hoje e amanhã. Brasília, DF: CONFEBRAS, 2012.

NORTH, D. Teoria da localização e crescimento econômico regional. In: SCHWARTZMAN, Jacques (Org.). Economia regional: textos escolhidos. Belo Horizonte: CEDEPLAR, 1977. p. 291-313.

OLIVEIRA, Nestor Braz de. Cooperativismo: guia prático. 2. ed. Porto Alegre: Organização das Cooperativas do Estado do Rio Grande do Sul, 1984.

PEREIRA, Charla; MASSUQUETTI, Angélica; KRUTZMANN, Vanessa. Caracterização da atividade avícola no município de Boa Vista do Sul (RS). Organizações Rurais e Agroindustriais (UFLA), Lavras, v. 14, p. 91-107, 2012.

PINDYCK, Robert S.; RUBINFELD, Daniel L. Microeconomia.7. ed. São Paulo: Pearson Education do Brasil, 2010.

PINHEIRO, Marcos Antonio Henriques. Cooperativas de crédito: história da evolução normativa no Brasil. 6. ed. Brasília, DF: Banco Central do Brasil, 2008. Disponível em: <http://www.bcb.gov.br/htms/public/microcredito/livro_cooperativas_credito.pdf >. Acesso em: 24 ago. 2012.

PORTAL DO COOPERATIVISMO DE CRÉDITO. Maiores bancos do Brasil. [S.1., 2012]. Disponível em: <http://cooperativismodecredito.coop.br/mercado-financeiro/maiores-bancosbrasileiros/ >. Acesso em: 14 set. 2012.

RECH, Daniel. Cooperativas: uma alternativa de organização popular. Rio de Janeiro: DP\&A, 2000.

RODRIGUES, Roberto. Prefácio 1. In: MEINEN, Ênio; PORT, Márcio. O cooperativismo de crédito: ontem, hoje e amanhã. Brasília, DF: CONFEBRAS, 2012. p. 9-10.

SCHARDONG, Ademar. Cooperativa de crédito: instrumento de organização econômica da sociedade. Porto Alegre: Rigel, 2002. 
SICREDI SERRANA RS. História da Sicredi Serrana RS. Carlos Barbosa, 2012.

Disponível em: <http://www.sicrediserranars.com.br/institucional/historia-da-sicredi-serranars>. Acesso em: 12 out. 2012.

SICREDI SERRANA RS. Relatório anual Sicredi Serrana RS 2014. Carlos Barbosa, 2015. SILVA, Christian Luiz da; LOURENÇO, Marcus; SALANEK FILHO, Pedro. Capital social e cooperativismo no processo de desenvolvimento sustentável local: teorias e aplicações ao caso da Cooperativa Bom Jesus - Lapa/PR. In: ENCONTRO DA ANPAD, 30., 2006, Salvador. Trabalhos apresentados... Curitiba: ANPAD, 2006. Disponível em: <http://www.anpad.org.br/enanpad/2006/dwn/enanpad2006-eorc-2945.pdf>. Acesso em: 13 out. 2012.

SMITH, Adam. A riqueza das nações: investigação sobre sua natureza e suas causas. 2. ed. São Paulo: Nova Cultural, 1985.

Recebido em 21.10.14

Aprovado em 02.10.15 


\section{APÊNDICE A - TESTES DA RAIZ UNITÁRIA}

O teste da Raiz Unitária procura verificar se a série temporal é estacionária ou não estacionária. De uma maneira geral, uma série é estacionária se sua média e sua variância não variam sistematicamente ao longo do tempo. A hipótese nula a ser considerada para as variáveis é que as mesmas apresentam série temporal estacionária. Se a hipótese nula for rejeitada, a série temporal é considerada não estacionária. Para verificar se a hipótese nula é ou não aceita, verifica-se a estatística tau ou teste de tau, conhecido na literatura como teste de Dickey-Fuller (GUJARATI, 2006).

É importante destacar que, para cada série temporal das variáveis, o nível de significância considerado foi de $1 \%$, sendo que o intervalo para o teste com constante fica entre $-3,75$ e 3,75 e para o teste com constante e tendência o intervalo fica entre $-4,38$ e 4,38. Portanto, se as estatísticas de tau estão dentro dos intervalos de confiança, de acordo com as evidências amostrais, a hipótese nula é aceita. Assim, o teste da Raiz Unitária foi aplicado para cada variável do modelo, sendo os resultados obtidos apresentados na Tabela 8 a seguir.

Tabela 8: Resumo dos resultados do Teste de Dickey-Fuller para as variáveis do modelo

\begin{tabular}{c|c|c}
\hline \multicolumn{2}{c}{ Teste de Dickey-Fuller } \\
\hline Variável & Estatística tau com constante & Estatística tau com constante e tendência \\
\hline Agricultura & $-1,094$ & $-3,410$ \\
Indústria & 1,275 & $-2,811$ \\
Serviços & 0,340 & $-1,057$ \\
PIB_BVS & 0,203 & $-1,221$ \\
PIB_RS & 4,222 & 0,265 \\
PIB_BRASIL & 0,901 & $-8,721$ \\
Cooperativa & $-1,088$ & $-1,784$ \\
\hline
\end{tabular}

Fonte: Elaborado pelos autores a partir do software Gretl 1.9.12.

Após a aplicação do Teste de Dickey-Fuller para as variáveis, de acordo com as evidências amostrais apresentadas na Tabela 8, verificou-se que as variáveis PIB_RS e PIB_BRASIL apresentaram raiz unitária em pelo menos em um de seus testes. Assim, a hipótese nula de estacionariedade foi rejeitada, sendo que a série temporal destas variáveis não é estacionária. As demais variáveis, como Agricultura, Indústria, Serviços, PIB_BVS e Cooperativa não apresentam raiz unitária, assim, suas séries temporais são consideradas estacionárias e adequadas para o modelo. 